\title{
1 Improving investigation of wind turbine optimal site matching through the
}

\section{self-organizing maps}

Giovanni Gualtieri

\author{
Firenze, Italy
}

\begin{abstract}
Corresponding author. Phone: +39 55 3033743, Fax: +3955 308910 .
E-mail address: g.gualtieri@ibimet.cnr.it (G. Gualtieri).
\end{abstract}

\begin{abstract}
A wind turbine (WT) site optimization procedure was developed and applied on two different onshore and one offshore sites, supplied with tall met masts and belonging to exemplary wind climates. In addition to detecting the most suitable WT for each site, Kohonen's self-organizing maps (SOMs) were employed to improve investigation of those parameters mostly influencing site optimization. Three years (2013-2015) of 1-h vertical observations from local met masts and a database of 377 onshore and 23 offshore commercial WTs were used.
\end{abstract}

As a result, maximizing capacity factor $(C F)$ was confirmed as a good objective function, though not the best, which was minimizing levelized cost of energy $(L C o E)$. In general, these two conditions do not necessarily match: variously setting WT parameters may either result in an $L C o E$ reduction or $C F$ increase, but both conditions do not occur concurrently. A key finding was that minimum $L C O E$ cannot be achieved by indefinitely increasing the WT hub height, but rather through detection of an optimum value obtained as a unique solution of the optimization procedure. Furthermore, the capability of SOM to recognise the cluster structure of all parameters influencing WT site optimization shed further light on their mutual relationship, thus proving to be an ideal tool 
27 to address the non-convex nature of this issue.

28

29 Keywords:

30

31 Optimal site matching; Wind resource vertical profile; Wind turbine database; Capacity factor (CF);

32 Levelized cost of energy (LCoE); Self-organizing map (SOM) 


\begin{tabular}{|c|c|c|}
\hline 34 & \multicolumn{2}{|c|}{ Nomenclature } \\
\hline 35 & & \\
\hline 36 & Abbreviatic & ons \\
\hline 37 & WT & wind turbine \\
\hline 38 & PL & power law \\
\hline 39 & ASL & above sea level \\
\hline 40 & ANN & artificial neural network \\
\hline 41 & $\mathrm{SOM}$ & self-organizing map \\
\hline 42 & MinLCoE & minimum levelized cost of energy \\
\hline 43 & $\mathrm{MaxCF}$ & maximum capacity factor \\
\hline 44 & TR & top-right \\
\hline 45 & $\mathrm{BR}$ & bottom-right \\
\hline 46 & $\mathrm{TL}$ & top-left \\
\hline 47 & BL & bottom-left \\
\hline 48 & & \\
\hline 49 & Variables & \\
\hline 50 & $v$ & wind speed $[\mathrm{m} / \mathrm{s}]$ \\
\hline 51 & $z$ & height of observations [m] \\
\hline 52 & $\alpha$ & wind shear exponent [-], Eq. (2) \\
\hline 53 & $c$ & Weibull scale factor $[\mathrm{m} / \mathrm{s}]$ \\
\hline 54 & $k$ & Weibull shape factor $[-]$ \\
\hline 55 & $v_{m}$ & mean wind speed $[\mathrm{m} / \mathrm{s}]$ \\
\hline 56 & $v_{\text {median }}$ & median wind speed $[\mathrm{m} / \mathrm{s}]$ \\
\hline 57 & $v_{m p}$ & most probable wind speed $[\mathrm{m} / \mathrm{s}]$, Eq. (4) \\
\hline 58 & $v_{m e}$ & wind speed carrying maximum energy $[\mathrm{m} / \mathrm{s}]$, Eq. (5) \\
\hline 59 & $\rho$ & air density $\left[\mathrm{kg} / \mathrm{m}^{3}\right]$, Eq. (7) \\
\hline
\end{tabular}




\begin{tabular}{|c|c|c|}
\hline 60 & $P_{\text {atm }}$ & atmospheric pressure [mbar] \\
\hline 61 & $T$ & air temperature $[\mathrm{K}]$ \\
\hline 62 & $P$ & wind power density $\left[\mathrm{W} / \mathrm{m}^{2}\right]$, Eq. (9) \\
\hline 63 & $E_{a}$ & wind energy generated by an ideal WT [MWh/y], Eq. (11) \\
\hline 64 & $H_{h u b}$ & WT hub height $[\mathrm{m}]$ \\
\hline 65 & $P_{r}$ & WT rated power $[\mathrm{kW}]$ \\
\hline 66 & $E_{r}$ & WT rated energy $[\mathrm{MWh} / \mathrm{y}]$ \\
\hline 67 & $D$ & WT rotor diameter $[\mathrm{m}]$ \\
\hline 68 & $A$ & WT rotor diameter area $\left[\mathrm{m}^{2}\right]$ \\
\hline 69 & $v_{i}$ & WT cut-in wind speed $[\mathrm{m} / \mathrm{s}]$ \\
\hline 70 & $v_{r}$ & WT rated wind speed $[\mathrm{m} / \mathrm{s}]$ \\
\hline 71 & $v_{o}$ & WT cut-off wind speed $[\mathrm{m} / \mathrm{s}]$ \\
\hline 72 & $\Phi$ & WT design ratio [-], Eq. (17) \\
\hline 73 & $\eta_{r}$ & WT rated efficiency [-], Eq. (18) \\
\hline 74 & $\beta$ & intensity ratio [-], Eq. (19) \\
\hline 75 & $v_{r} / c$ & normalized rated speed [-], Eq. (20) \\
\hline 76 & $\eta_{T}$ & WT energy efficiency [-], Eq. (21) \\
\hline 77 & $A_{W T}$ & WT availability [\%], Eq. (16) \\
\hline 78 & $A E Y$ & annual energy yield [MWh/y], Eq. (14) \\
\hline 79 & $C F$ & capacity factor [\%], Eq. (15) \\
\hline 80 & $L C o E$ & levelized cost of energy [\$/MWh], Eq. (22) \\
\hline 81 & $C_{\text {initial }}$ & initial capital cost (capital expenditure) [\$], Eq. (23) \\
\hline 82 & $C_{W T}$ & WT capital cost [\$], Eq. (24) \\
\hline 83 & $C_{i}$ & annual cost (operational expenditure) at year $i[\$ / \mathrm{kW} / \mathrm{y}]$ \\
\hline
\end{tabular}




\section{Introduction}

86

Wind energy optimal site matching deals with the best pairing between a given site and a selected range of WTs [1]. This involves wind engineers or WT manufacturers in analysing and determining, during the planning stage of a wind energy project, which type of WTs is most suitable for a given site, or vice versa [2]. In the past literature, several criteria have been proposed to implement this pairing procedure. One of the most popular because of its simplicity, for example, is the one developed by Jangamshetti and Rau [3], based on identifying the optimum WT performance index curve, obtained from the WT normalized power curves, so as to yield higher energy production at a higher capacity factor. In fairness, a common issue affecting the latter and most of similar studies is the tendency to simplify, by implementing various models, the characteristics of either the site or WTs, or even both. Indeed, various shortcomings may be recognised in their approach, including: (i) site's wind speed vertical profile is neglected [1-8]; (ii) a very small number of WTs, not sufficiently representative of the commercial market (as shown, e.g., by Carrillo et al. [9]), is considered [3,5,7,8,10-13]; (iii) manufacturer WT power curves are not explicitly treated but just fitted by means of polynomial, exponential, cubic or quadratic expressions $[1-3,8,12,14]$; (iv) capacity factor (or an index being a function of it) is taken as the unique optimization parameter [1-3,7,11]; (v) applications on offshore locations are numbered (with rare exceptions such as, e.g., $[5,7,15])$.

Actually, a key issue is to turn "optimization" from a theoretical into a practical meaning, and thus to assign it a clear and unambiguous definition through recognition of the parameter required to be "optimized", i.e. the objective function [6]. Taking this into consideration, the capacity factor alone cannot provide overall information on WT characteristics, as further parameters such as WT efficiency should also be taken into account [10]. On the other hand, economic viability of a wind energy project is a key factor to be considered when installing a wind farm [16], and thus a cost optimization should necessarily be accomplished, as demonstrated, e.g., by [4,5,12-14,17-20]. To 
111 this aim, the levelized cost of energy - rather than the capacity factor - proved to be the most robust

112 objective function as it appropriately describes the potential profitability of a wind energy project

113 [13,21]. A popular cost reduction technique is to increase the WT rated power by making WTs larger.

114 However, as noticed by Ashuri et al. [20], it is not clear whether further WT upscaling beyond the

115 existing 5-7 MW range is both technically feasible and economically attractive: the advantage of

116 upscaling is the increase in energy yield, while its disadvantage is the increase in initial capital cost.

117 This study intends to take a step forward in optimal site matching, paying specific attention to

118 practical wind energy issues. Therefore, sites' features were thoroughly assessed by constructing

119 wind resource vertical profiles, while WTs characteristics were not modelled, but rather explicitly

120 treated. Furthermore, instead of maximizing capacity factor (yet retained for comparison),

121 minimizing levelized cost of energy was the adopted objective function. The goal of this study is

122 twofold: (i) to detect the most suitable WT for each site among all commercially available WTs and

123 analyse the issues behind; (ii) to shed further light, via the use of the self-organizing maps (SOMs),

124 on those WT parameters mostly influencing site optimization. In recent years, Kohonen's SOMs

125 [22] have been successfully applied in various scientific disciplines to recognize complex patterns

126 and find hidden structures in high-dimensional datasets. In wind energy studies, SOMs have been

127 applied, e.g., in daily electric load profile forecasting [23], wind power forecasting [24,25], wind

128 speed spatial interpolation [26], WT performance assessment [27], and WT fault diagnosis [28]. To

129 the best of the Author's knowledge, although the strongly non-convex nature of WT site

130 optimization, the use of the SOMs has never been applied to address this issue yet.

131 Two different onshore and one offshore sites, each with a tall met mast installed, have been

132 considered: a flat and sea-level inland site (Cabauw), an elevated mountain site with fairly complex

133 terrain (Boulder), and an open-sea offshore platform (FINO3). Three years (from 01/01/2013 to

$13431 / 12 / 2015)$ of 1-h observations of wind speed, air temperature, and atmospheric pressure collected

135 at various heights from local met masts have been used. An extensive database including 377

136 onshore and 23 offshore commercial WTs has also been used. 


\subsection{Wind speed vertical extrapolation}

141 The PL is the most widely used wind speed extrapolating model for wind energy studies since it 142 is the most accurate as well as the simplest [29]. According to the PL, surface wind speed is 143 vertically extrapolated as [30]:

$144 \quad v_{2}=v_{1}\left(\frac{z_{2}}{z_{1}}\right)^{\alpha}$

145 where $v_{1}$ and $v_{2}$ are wind speeds at heights $z_{1}$ and $z_{2}$, respectively. The PL is an empirical model best

146 fitting wind speed profiles up to $300 \mathrm{~m}$ from the ground [29]. From Eq. (1), $\alpha$ can be measured once 147 concurrent records of $v_{1}$ and $v_{2}$ are available:

$148 \quad \alpha=\frac{\ln \left(v_{2} / v_{1}\right)}{\ln \left(z_{2} / z_{1}\right)}$

\subsection{Site's wind energy characteristics}

Since best fitting real wind speed data (e.g. [31]), the two-parameter Weibull probability density

152 function $f(v)$ is commonly used to express wind speed frequency distribution and estimate wind 153 power density [32]. It is defined as:

$$
f(v)=\frac{k}{c}\left(\frac{v}{c}\right)^{k-1} \exp \left[-\left(\frac{v}{c}\right)^{k}\right]
$$

where $c$ is the scale parameter, and $k$ the shape parameter. Once $c$ and $k$ have been estimated (e.g. based on [33]), meaningful wind speed characteristics can be calculated, such as the most probable wind speed [10]:

$158 \quad v_{m p}=c\left(\frac{k-1}{k}\right)^{1 / k}$, 
$160 \quad v_{m e}=c\left(\frac{k+2}{k}\right)^{1 / k}$

161 For an area $A$ of the WT rotor disc and a given wind speed $v$, site's available wind power is [34]:

$162 P(v)=\frac{1}{2} \rho A v^{3}$

163 where $\rho$ is the air density, which may be calculated as [35]:

$164 \rho=\frac{P_{a t m}}{R \times T}$

165 with $P_{a t m}$ the atmospheric pressure [mbar], $R$ the specific gas constant for air [287.053 J/kg K], and $166 T$ the air temperature $[\mathrm{K}]$.

167 When elevated $P_{a t m}$ is not available, the $P_{\text {atm }}$ vertical profile may be approximated by [36]:

$168 \quad P_{a t m}(z)=P_{0} \cdot \exp [-(0.0342 / T) \cdot z]$

169 where $P_{0}$ is the atmospheric pressure at ground level [mbar].

170 Integrating $P(v) / A$ over all possible wind speeds multiplied by the fraction of time each wind 171 speed is experienced, from Eq. (6) site's wind power density $P$ based on Weibull probability density 172 function can be expressed as [10]:

173

$P=\frac{1}{A} \int_{0}^{\infty} P(v) f(v) d v=\frac{1}{2} \rho c^{3} \Gamma\left(\frac{k+3}{k}\right)$

where $\Gamma$ is the Gamma function.

\subsection{Wind energy output}

The mechanical power $P_{m}(v)$ extracted from site's available wind power is [37]:

$P_{m}(v)=C_{p} P(v)=\frac{1}{2} C_{p} \rho A v^{3}$

where $C_{p}$ is WT power coefficient, whose theoretical maximum value (0.593) is the Betz limit [38].

180 Wind energy generated by an ideal WT over a period $\bar{t}$ can be calculated as [34]:

181

$$
E_{a}=\bar{t} \int_{0}^{\infty} P_{m}(v) f(v) d v=\bar{t} C_{p} \int_{0}^{\infty} P(v) f(v) d v
$$


with $C_{p}$ equal to the Betz limit (0.593).

183

The electric power output $P_{e}(v)$ of an actual WT is given by $[6,39]$ :

184

$$
P_{e}(v)=\eta_{m} \eta_{e} P_{m}(v)=\frac{1}{2} C_{p} \eta_{m} \eta_{e} \rho A v^{3}
$$

185

186

187

188

where $\eta_{m}$ and $\eta_{e}$ are the efficiencies of mechanical transmission and electric generation [6].

For WTs operating at constant $P_{r}$ with maximum efficiency between $v_{r}$ and $v_{o}$, the relation between $P_{e}(v)$ and the available wind speed $v$ can be mathematically approximated by [37]:

$$
P_{e}(v)= \begin{cases}0 & , 0 \leq v<v_{i} \\ \left(a+b v+c v^{2}\right) P_{r}, & v_{i} \leq v<v_{r} \\ P_{r} & , v_{r} \leq v<v_{o} \\ 0 & , v>v_{o}\end{cases}
$$

where the constants $a, b$, and $c$ are functions of $v_{i}$ and $v_{r}$, as provided, e.g., in [37].

Combining Eqs. (12) and (13), actual energy production $(E)$ of a WT over a 1 -year period ( $\bar{t}$ $=8760$ hours), or $A E Y$, is [10]:

$$
A E Y=E=\bar{t} \int_{0}^{\infty} P_{e}(v) f(v) d v=\bar{t} \int_{0}^{\infty} \eta_{m} \eta_{e} P_{m}(v) f(v) d v=\bar{t} P_{r} \int_{v_{i}}^{v_{r}}\left(a+b v+c v^{2}\right) f(v) d v+\bar{t} P_{r} \int_{v_{r}}^{v_{o}} f(v) d v
$$

Capacity factor $C F$ is the ratio of $A E Y$ to the energy $\left(E_{r}\right)$ that the WT could have produced if operated at its rated power over the same period [34]:

$$
C F=\frac{E}{E_{r}}
$$

$$
\text { WT availability } A_{W T} \text { is defined as [37,40]: }
$$

$A_{W T}=M T B F /(M T B F+M T T R)$

where $M T B F$ is the mean time between failures and MTTR the mean time to repair. In a wind farm reliability analysis, availability is a key measure of performance as it is closely related to energy production and revenues [41].

\subsection{Wind turbine design and "paired" parameters}

In the past studies, crucial parameters have been introduced to classify WT characteristics, as 
well as to assess on-site WT performances once paired with site's characteristics.

205 WT design parameters include the WT design ratio [6]:

$206 \Phi=v_{r} / v_{i}$,

207 and WT rated efficiency $[6,10]$ :

$\eta_{r}=\frac{P_{r}}{(1 / 2) \rho A v_{r}^{3}}$

"Paired" parameters (i.e. between WT and site) include the intensity ratio [6]:

$210 \quad \beta=v_{m} / v_{i}$,

211 the normalized rated speed [3]:

$212 v_{r} / c$,

213 and WT energy efficiency, i.e. the ratio between actual WT energy output $(A E Y)$ and wind energy 214 generated by an ideal WT $\left(E_{a}\right)[10]$ :

$215 \quad \eta_{T}=\frac{A E Y}{E_{a}}$.

\subsection{Cost estimation}

The cost of a wind farm project varies significantly over time and location, generally depending on the number of WTs, the distance of the site from the WT manufacturer, land leasing, foundations, planning and licensing, grid connection, distribution system, etc. [34]. A careful evaluation of all these components spanning the entire project's lifetime should therefore be performed. Due to the large number of WT models employed, in this study an exact cost evaluation for each WT appeared unfeasible, vice versa, as well as an evaluation of the entire wind power project (wind farm layout optimization), which on the other hand is beyond the scope of the work. Therefore, a simplified approach for estimating each project's component was adopted. In addition, cost parameters have been estimated taking the 2016 US market as a reference and [\$] as currency.

The levelized cost of energy $(L C o E)$ is recognised as the economic "figure-of-merit" most 
of all costs of a fully operational wind farm over the project's lifetime with financial flows

230 discounted to a common year [43]. $L C o E$ for a wind energy project is calculated as [13]:

$$
L C o E=\frac{C_{\text {initial }}+\sum_{i=1}^{n} C_{i} /(1+d)^{i}}{\sum_{i=1}^{n} A E Y /(1+d)^{i}}
$$

where $C_{\text {initial }}$ is the initial capital cost (capital expenditures), $C_{i}$ the annual cost at year $i$ (operational expenditures), $i$ the year since installation, $n$ the operational life, and $d[\%]$ the interest rate of the investment.

The initial capital cost $C_{\text {initial }}$ of a wind farm project is the sum of the WT capital cost $\left(C_{W T}\right)$, the balance of system, and financial costs [44]. In general, $C_{W T}$ can be considered as a quite constant fraction ( $p$ ) of $C_{\text {initial }}$. In their extensive review on the US market for the year 2013, Moné et al. [44] reported $C_{W T}$ to account for $68 \%$ of $C_{\text {initial }}$ for onshore, and $32 \%$ for offshore projects. Therefore, using these percentages $(p)$ for onshore $(68 \%)$ and offshore $(32 \%)$ projects, $C_{\text {initial }}$ can be approximated as:

$C_{\text {initial }}=C_{W T} / p$

It is clear that, as also noted by Snel [45], for offshore locations the use of Eq. (23) leads to higher uncertainties in the $C_{\text {initial }}$ computation than for onshore locations, as at offshore locations it is the balance of system (including foundation, installation and electrical cable costs) to play the major role in the cost (52\% in US, according to Moné et al. [44]).

To calculate $C_{W T}$, the parametric approach by Perkin et al. [13] was applied, who expressed $C_{W T}$ as an increasing function of $P_{r}, D$ and $H_{h u b}$. Relying on the WT design cost and scaling model developed by Fingersh et al. [46], based on the 2002 US market, Perkin et al. [13] proposed a single $C_{W T}$ expression obtained by fitting the 24 cost equations (one for each WT component) developed by Fingersh et al. [46]. The $C_{W T}$ expression, detailed as Eq. (9) in Perkin et al. [13], is in the form:

$C_{W T}=f_{i} * f\left(P_{r}, D, H_{h u b}\right)$

where $f_{i}$ is an inflation scaling factor (equal to 1.34) accounting for the US average inflation rate between 2002 and 2016. Of course, Eq. (24) is a more refined expression for $C_{W T}$ than those (e.g. 
[8]) only relating $C_{W T}$ to $P_{r}$.

Annual costs $C_{i}$, generally including operation and maintenance costs, have been derived from Moné et al. [44] as 50 [\$/kW/y] for onshore and 136 [\$/kW/y] for offshore projects.

\subsection{Self-organizing map}

The SOM is the result of the converged SOM algorithm, which is a type of unsupervised

learning ANN-based model that implements a nonlinear projection from a high-dimensional space of sensory or other input signals onto a low-dimensional (usually two-dimensional) regular grid (or lattice) of neurons [47]. The SOM converts complex, nonlinear statistical relationships between high-dimensional data into simple geometric relationships on a low-dimensional display [22]. Each neuron on the two-dimensional grid also has a $d$-dimensional weight (or prototype) vector, where $d$ is the dimension of the input vectors. Thus, SOM defines a nonlinear projection from the $d$ dimensional data space to the two-dimensional grid [48]. Mapping from the original data space to the grid of neurons is accomplished in an orderly fashion while preserving the most important topological and metric relationships of the primary data [47]. This means that data vectors close to each other in the data space tend to map to the same or close-by neurons in the grid. This makes visualization of the grid useful in exploring the relationships of variables and the possible cluster structure of the data [48].

The core of the SOM algorithm is the learning rule stated by Kohonen, which allows the topographic map to organize itself [49]. The algorithm defines an iterative training process where each input neuron is connected to all output neurons. Before the training, the data vectors have to be normalized such that the mean of each variable is 0 and the variance is 1 : this normalization method scales the data linearly, which preserves the structure of the absolute values of the measurements [50]. After initializing the neurons with values spanning the space of two dominant eigenvectors, the training proceeds in two alternating steps. Data vectors are first mapped to neurons by looking for the best-matching unit (or the winner neuron, i.e. the neuron with the closest prototype vector) 
using a Euclidean distance measure between the data vector and the set of neurons. Second, the

281 neurons are adapted to better represent the distribution of the data [50], and thus connected to 282 adjacent neurons by a neighbourhood function which determines the rate of change (i.e. the strength 283 of adaptation) of neighbouring neurons around the winner neuron [48]: this function dictates the 284 topology, or structure, of the map [51]. Typical neighbourhood functions are Gaussian, Cut 285 Gaussian, bubble, and Mexican hat [51]. This learning procedure is controlled by another two 286 parameters, both decreasing monotonically with the training steps: the learning rate and the 287 neighbourhood radius. The learning rate, comprised between 0 and 1 , specifies to what degree the 288 neurons generally adapt to a given input vector, while the neighborhood radius determines to what 289 degree neighborhood neurons adapt depending on their distance to the winner neurons [22]. For the 290 latter, an initial value higher than half the lattice's diameter is recommended [51].

291 In the case of a 2-dimensional grid, the neurons of the map can be arranged either on a hexagonal 292 or a rectangular lattice; the use of hexagonal lattice is usually recommended because all 6 293 neighbours of a neuron are at the same distance (as opposed to the 8 neighbours in a rectangular 294 lattice): this way the maps become smoother and more pleasing to the eye [51]. To assess whether 295 the map has properly adapted itself to the training data, thus helping choose suitable parameters, 296 two quality measures are commonly used: (i) the quantization error, measuring how good the map 297 can fit the input data, and (ii) the topographic error, measuring how well topology is preserved by 298 the map. 


\section{Sites and observations}

301

302

303

304

Two onshore and one offshore sites have been considered (Table 1): Cabauw (Netherlands), a flat and sea-level inland site supplied by a 213-m mast; Boulder (CO, USA), an elevated mountain site affected by a fairly complex terrain and supplied by the 82-m M2 mast; FINO3, an offshore platform $80 \mathrm{~km}$ off the coast in the North Sea (Germany) supplied by a 120-m mast. These sites are real cases approximately falling into three out of six exemplary wind climate sites as defined by Fuglsang et al. [5]. A detailed description of their characteristics may be found, e.g., in [30] for Cabauw, [52] for Boulder, and at http://www.fino3.de for FINO3.

\section{Table 1}

Characteristics of the met mast supplied application sites being investigated.

\begin{tabular}{llllll}
\hline $\begin{array}{l}\text { Location } \\
\text { (State, Country) }\end{array}$ & Operator & $\begin{array}{l}\text { Latitude } \\
(\text { deg N) }\end{array}$ & $\begin{array}{l}\text { Longitude } \\
\text { (deg E) }\end{array}$ & $\begin{array}{l}\text { Altitude } \\
\text { (m ASL) }\end{array}$ & Terrain, and land use \\
\hline $\begin{array}{l}\text { Cabauw } \\
\text { (Netherlands) }\end{array}$ & KNMI & $51^{\circ} 58^{\prime} 25^{\prime \prime}$ & $4^{\circ} 55^{\prime} 55^{\prime \prime}$ & -0.7 & $\begin{array}{l}\text { Flat, open pasture, } 50 \\
\text { km from the coast }\end{array}$ \\
$\begin{array}{l}\text { Boulder } \\
\text { (CO, USA) }\end{array}$ & NWTC & $39^{\circ} 54^{\prime} 38^{\prime \prime}$ & $-105^{\circ} 14^{\prime} 5^{\prime \prime}$ & 1855 & $\begin{array}{l}\text { Fairly complex, hills } \\
\text { with no trees } \\
\text { Offshore, } 80 \mathrm{~km} \text { off the } \\
\text { coast }\end{array}$ \\
$\begin{array}{l}\text { FINO3 } \\
\text { (Germany) }\end{array}$ & BSH & $55^{\circ} 11^{\prime} 42^{\prime \prime}$ & $7^{\circ} 9^{\prime} 30^{\prime \prime}$ & 0 & \\
\hline
\end{tabular}

A 3-year (01/01/2013-31/12/2015) observation dataset including 1-h wind speed, air temperature, and atmospheric pressure have been used. Table 2 reports, for each mast, the available sensor heights for each variable and their valid record percent. 


\section{Table 2}

319 Features of met masts and 1-h data samples (2013-2015) ${ }^{\mathrm{a}}$.

\begin{tabular}{lllll}
\hline Site & Mast height $(\mathrm{m})$ & Variable & Sensor heights $(\mathrm{m})$ & ${\text { Valid records }(\%)^{\mathrm{b}}}^{\mathrm{b}}$ \\
\hline Cabauw & 213 & Wind speed & $10,20,40,80,140,200$ & 98.08 \\
& & Temperature & $10,20,40,80,140,200$ & \\
& \multirow{4}{*}{82} & Pressure & 0 & \\
Boulder & \multirow{2}{*}{ Wind speed } & $10,20,50,80$ & 98.95 \\
& & Temperature & $2,50,80$ & \\
& \multirow{2}{*}{120} & Pressure & 0 & \multirow{2}{*}{82.49} \\
& & Wind speed & $50,60,70,80,90,100$ & \\
& & Temperature & $29,55,95$ & \\
& & Pressure & 23,94 & \\
\hline
\end{tabular}

${ }^{\mathrm{a}}$ Statistics for 26,280 1-h records over the period 01/01/2013-31/12/2015.

${ }^{\mathrm{b}}$ Concurrent valid records are considered for all variables and all sensor heights.

\section{Wind turbine database}

A total of 400 (377 onshore and 23 offshore) commercial WTs have been considered. Where they

were not directly available from the manufacturers' official websites, WT characteristics have been

obtained from the WindPower database [53]. All wind energy yield computations have been

performed by using an updated version of the wind resource assessment tool described in [54], where the 400-WT database was implemented.

A summary of main WT characteristics is provided by the histograms plotted in Fig. 1. Further

WT characteristics are shown in Figs. S1 and S2 of the supplementary material provided.

In order to assess availability $A_{W T}$, all analysed WTs have been grouped into four populations of

WT systems: (A) fixed-speed; (B) variable-speed with induction generator; (C) variable-speed with doubly fed induction generator; (D) variable-speed with direct-drive synchronous generator. Thus, depending on WT system, availability values have been assumed as: (A) 99.8\%; (B) 98.6\%; (C) (D) they have been derived from [56]. 

(averaging 1,520 \$/kW) for onshore WTs, and 1,080-3,275 \$/kW (averaging 1,560 \$/kW) for 340 offshore WTs. The reliability of Eq. (24) has been roughly assessed after comparison with some 341 updated outcomes from the literature. Onshore, for example, for WTs with $P_{r}$ ranging 1.8-2.0 MW 342 an average $C_{W T} / P_{r}$ of $1,320 \$ / \mathrm{kW}$ was achieved, being slightly higher than the $1,185 \$ / \mathrm{kW}$ value reported by Moné et al. [44] in US (year 2013) for land-based reference projects using $1.91 \mathrm{MW}$ 344 WTs; offshore, for WTs with $P_{r}$ between 3.6 and 5.0 MW an average $C_{W T} / P_{r}$ of $1,420 \$ / \mathrm{kW}$ was achieved, slightly lower than the $1,660 \$ / \mathrm{kW}$ value reported by Moné et al. [44] for offshore reference projects in US (year 2013) using 4.3 MW WTs. A further thorough comparison, performed against market prices, resulted in $C_{W T}$ estimates only slightly lower than costs reported, e.g., for some WTs by Boudia and Guerri [57]: 940 k\$ for Nordex N50-800 (vs. 970 k\$); 1,170 k\$ for Neg-Micon 60-1000 (vs. 1,315 k\$); 1,720 k\$ for Vestas V66-1.65 (vs. 2,000 k\$), and 3,300 k\$ for Vestas V90-3.0 (vs. 3,600 k\$).

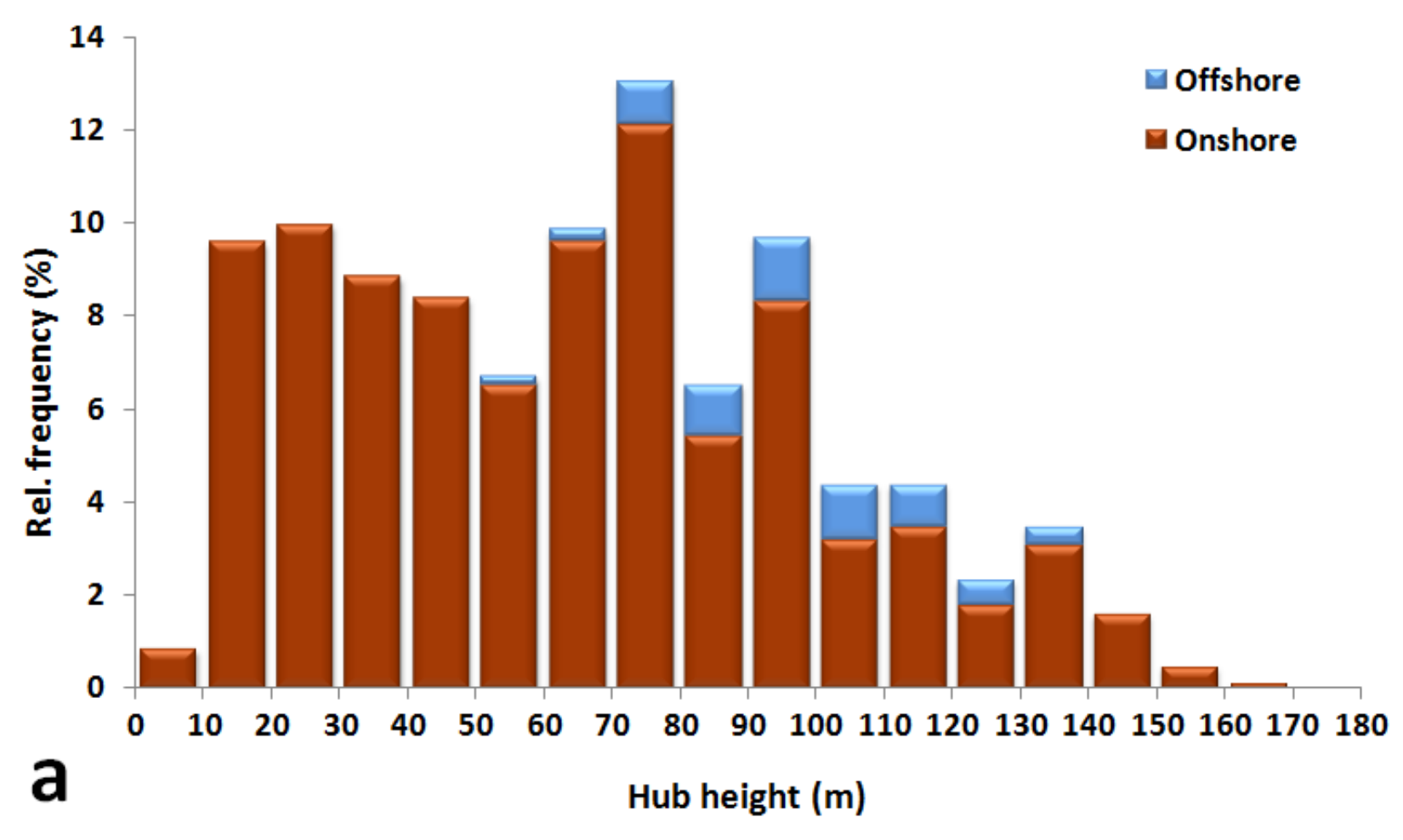



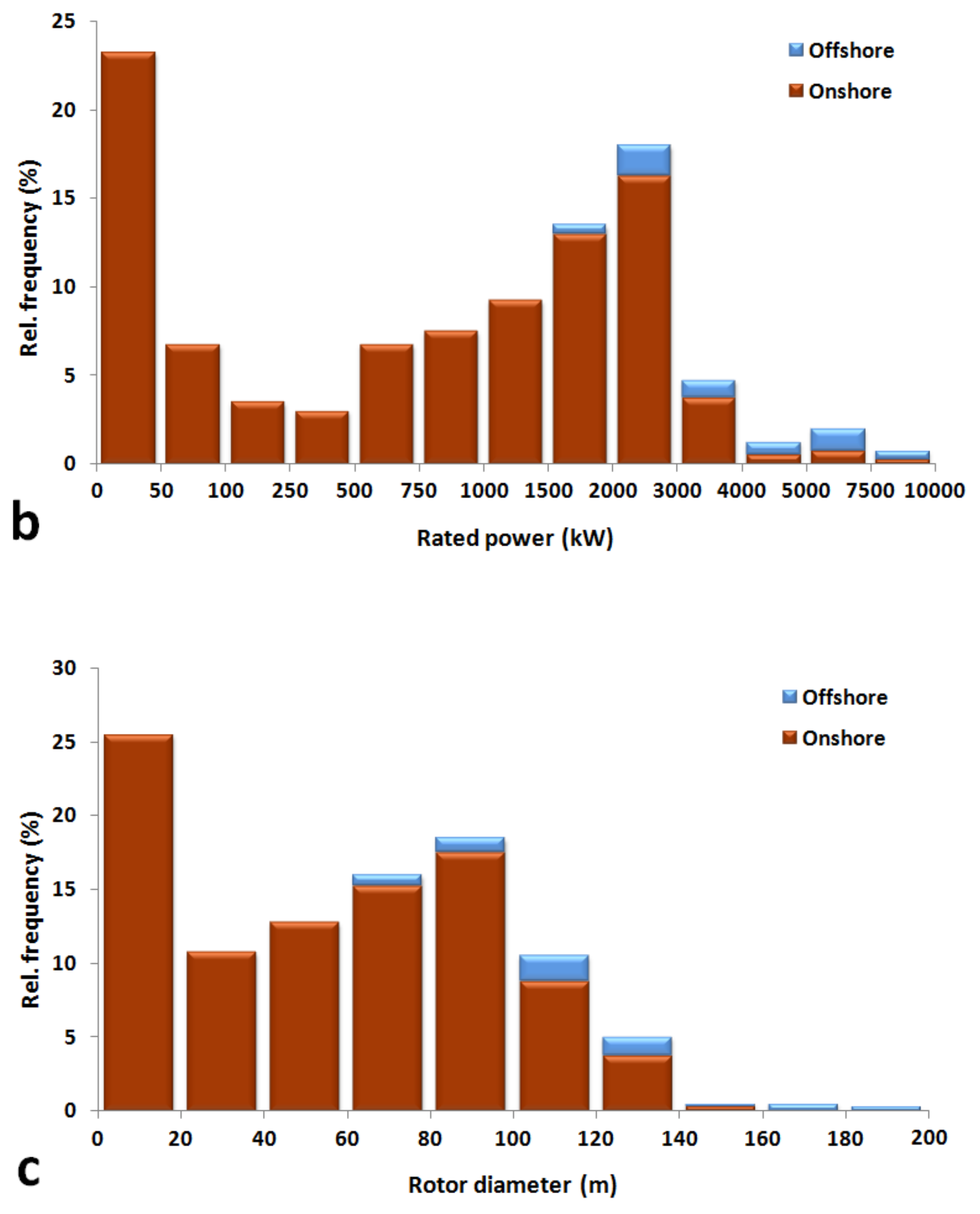


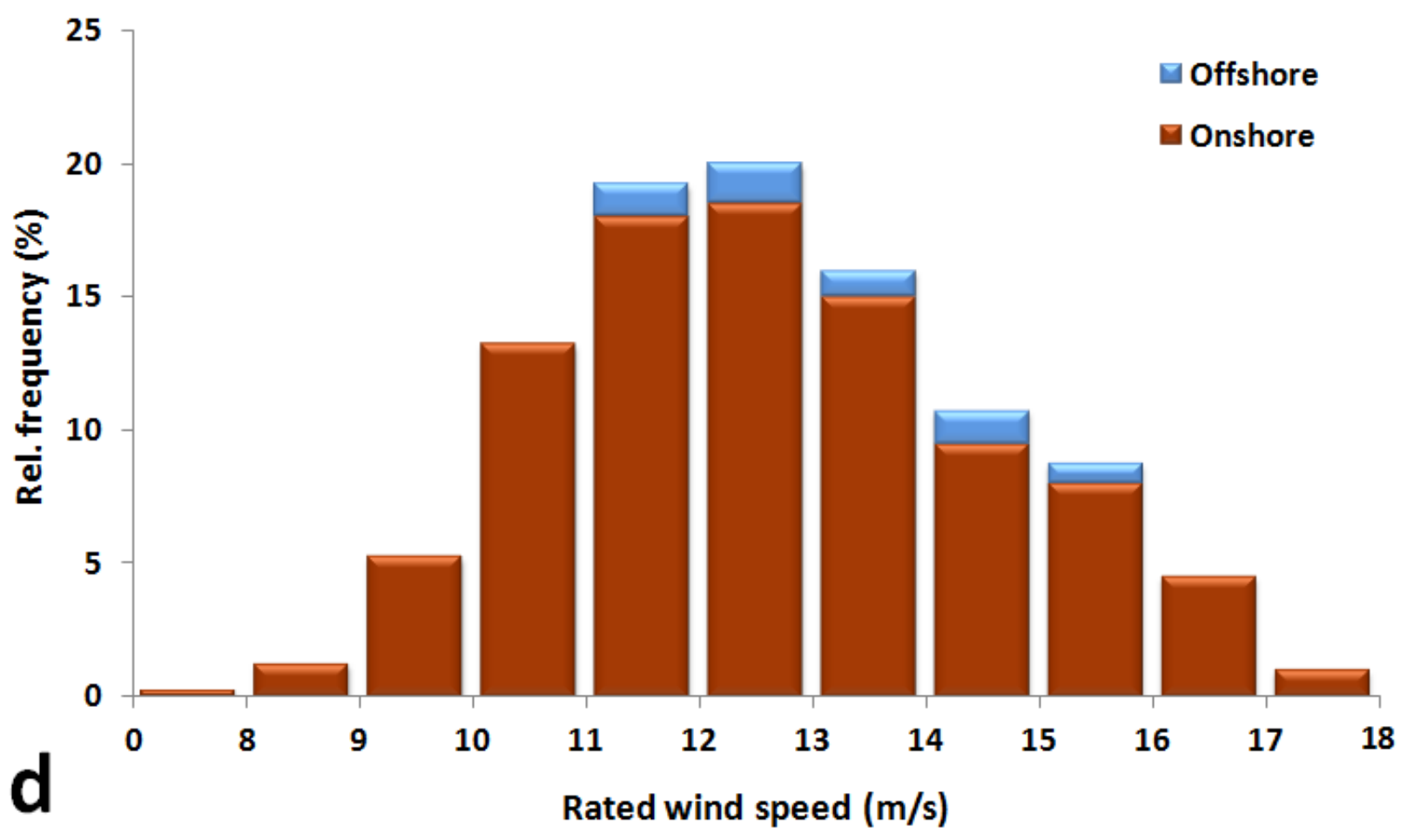

359 Fig. 1. Histograms of the main characteristics of all onshore and offshore WTs analysed: (a) hub 360 height; (b) rated power; (c) rotor diameter; (d) rated wind speed. 


\subsection{Application details}

WT optimal site matching has been addressed targeting two objective functions: minLCoE, and
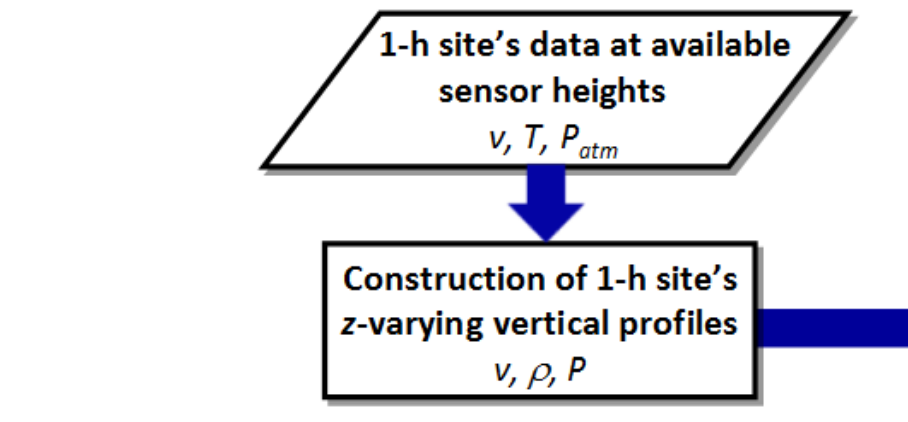

for each z step:

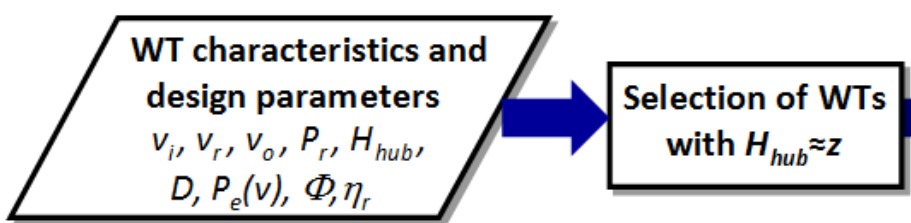

Fig. 2. Flowchart of the WT optimal site matching procedure.

For each location, the following phases were employed: (i) construction of 1-h $z$-step vertical profiles of $v, \rho$ and $P$; (ii) for each $z$ step, computation of site's annual wind resource and wind energy characteristics $\left(v_{m}, v_{\text {median }}, v_{m p}, v_{m e}, c, k, \rho\right.$ and $P$ ); (iii) for each $z$ step, computation of annual 
each $z-H_{h u b}$ pairing, selection of the two WTs achieving minLCoE and maxCF, and compilation of the two respective $z$-varying lists of candidate WTs; (v) final detection, across the whole vertical profile of candidate WTs, of the unique WT minimizing $L C o E$ and of the one maximizing $C F$. Therefore, search for site optimization was a 2-phase stepwise procedure aimed at detecting, for each objective function: (i) a vertical profile of candidate WTs; (ii) the unique WT solution of the optimization procedure among all candidate WTs. Thus, each objective function was applied twice.

Considering the $H_{h u b}$ values of the available WT database (Fig. 1a), $z$ ranged from 10 to $160 \mathrm{~m}$ for the onshore sites, and from 50 to $150 \mathrm{~m}$ for the offshore site. A common step of $2 \mathrm{~m}$ was used in $z$ variation for vertical profiling. In the $H_{h u b}$-to- $z$ vertical approximation, a maximum tolerance of \pm 2 $\mathrm{m}$ between $H_{h u b}$ and $z$ was set for the onshore sites, and $\pm 5 \mathrm{~m}$ for the offshore site.

Vertical profiles were constructed based on 3-year 1-h records collected at the available sensor heights (Table 2). At heights where information was not available variables were vertically interpolated/extrapolated for each hour: wind speed profiles were calculated through the PL (Eq. 1) using $\alpha$ values measured each hour between the nearest heights (Eq. 2); $\rho$ profiles, needed to calculate $P$ profiles via Eq. (9), were derived using Eq. (7) after linearly interpolating $T$, while $P_{a t m}$ was vertically extrapolated using Eq. (8) as a function of $P_{a t m}$ at the lowest sensor height $\left(P_{0}\right)$. For heights above the highest available sensors (at Boulder and FINO3), wind speed profiles were extrapolated using the same $\alpha$ values of the lower-range wind speed profiles, while $T$ profiles were extrapolated using the same gradients of the lower-range $T$ profiles.

In wind energy computations, for each site WT total power losses (Table 3) have been accounted, based on the approach described in [32,35], as a combination of: (i) WT-specific losses (for gearbox, generator, converter, and unavailability \& repair); (ii) site-specific losses (for electric grid connection and icing). As for (i), losses were varied by WT system, with values retrieved from [55] (systems A-C), and from [58] (systems D). 
402 Losses (\%) by WT system accounted for energy yield calculations at each site ${ }^{\mathrm{a}, \mathrm{b}}$.

\begin{tabular}{|c|c|c|c|c|c|c|c|c|c|c|c|c|}
\hline & \multicolumn{12}{|l|}{ Site } \\
\hline & \multicolumn{4}{|c|}{ Cabauw } & \multicolumn{4}{|c|}{ Boulder } & \multicolumn{4}{|c|}{ FINO3 } \\
\hline & \multicolumn{12}{|c|}{ WT system } \\
\hline & A & $\mathrm{B}$ & $\mathrm{C}$ & $\mathrm{D}$ & $\mathrm{A}$ & B & $\mathrm{C}$ & $\mathrm{D}$ & $\mathrm{A}$ & B & $\mathrm{C}$ & $\mathrm{D}$ \\
\hline Gearbox & 4.0 & 3.0 & 3.0 & 0.0 & 4.0 & 3.0 & 3.0 & 0.0 & 4.0 & 3.0 & 3.0 & 0.0 \\
\hline Generator & 2.5 & 2.2 & 1.5 & 3.5 & 2.5 & 2.2 & 1.5 & 3.5 & 2.5 & 2.2 & 1.5 & 3.5 \\
\hline Converter & 0.0 & 2.4 & 0.8 & 4.7 & 0.0 & 2.4 & 0.8 & 4.7 & 0.0 & 2.4 & 0.8 & 4.7 \\
\hline $\begin{array}{l}\text { Unavailab. } \\
\& \text { repair }\end{array}$ & 0.2 & 1.4 & 1.2 & 0.1 & 0.2 & 1.4 & 1.2 & 0.1 & 0.2 & 1.4 & 1.2 & 0.1 \\
\hline $\begin{array}{l}\text { Grid } \\
\text { connection }\end{array}$ & 1.0 & 1.0 & 1.0 & 1.0 & 1.0 & 1.0 & 1.0 & 1.0 & 2.0 & 2.0 & 2.0 & 1.0 \\
\hline Icing & 3.0 & 3.0 & 3.0 & 3.0 & 5.0 & 5.0 & 5.0 & 3.0 & 3.0 & 3.0 & 3.0 & 3.0 \\
\hline Other & 0.0 & 0.0 & 0.0 & 0.0 & 0.0 & 0.0 & 0.0 & 0.0 & 0.0 & 0.0 & 0.0 & 0.0 \\
\hline Total & 10.30 & 12.33 & 10.07 & 11.74 & 12.15 & 14.14 & 11.93 & 13.56 & 11.20 & 13.22 & 10.98 & 12.63 \\
\hline
\end{tabular}

${ }^{\mathrm{a}}$ Losses due to gearbox, generator, converter, and unavailability \& repair are varied based on WT 404 system: their values are taken from [55] (systems A-C), and from [58] (systems D).

${ }^{\mathrm{b}}$ Since the study is focussed on single WTs, array losses were not considered.

For each WT, LCoE was calculated based on the simplified approach described in section 2.5, 408 where the following was set in Eq. (22): $n=20$ years; $d=5 \%$.

Tables 4 and 5 summarize the statistics of WT optimal site matching. For all locations, annual average vertical profiles of wind speed Weibull distributions (Fig. 3), site's characteristics (Figs. 4a, $4115 \mathrm{a}$, and 6a), and optimization conditions (Figs. 4b, 5b, and 6b) are presented. Annual vertical profiles 412 of WT design parameters $\left(\Phi\right.$ and $\left.\eta_{r}\right)$ and paired parameters $\left(\beta, v_{r} / c\right.$ and $\left.\eta_{T}\right)$ by optimization 413 condition are also shown in supplementary material (Figs. S3, S4, and S5). 

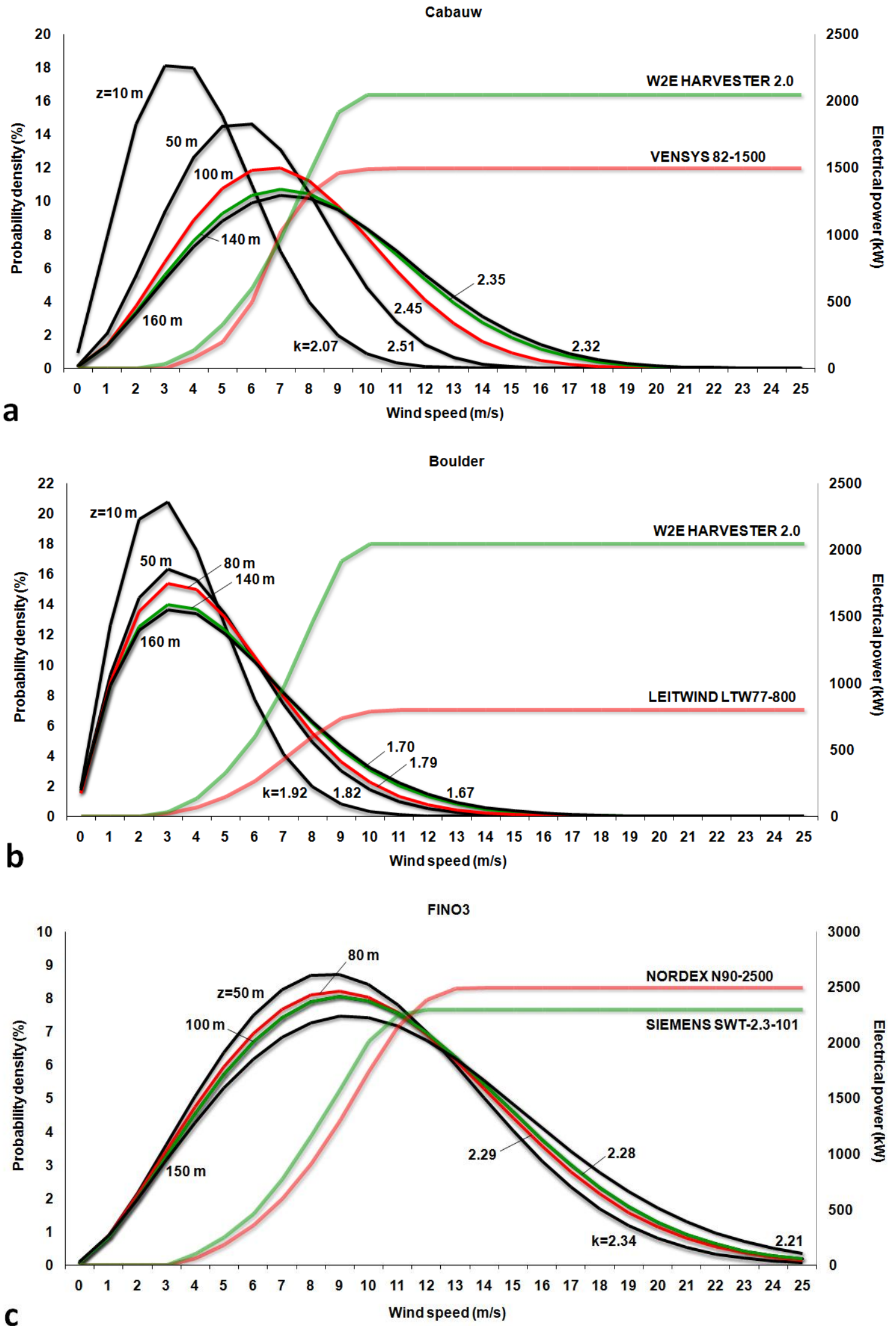

418 Fig. 3. Height variation of annual wind speed Weibull distributions profiled 2013-2015 at: (a)

419 Cabauw; (b) Boulder; (c) FINO3. Height-related distributions corresponding to WTs achieving $420 \operatorname{minLCoE}$ (red) and maxCF (green) and their power curves are also shown (see Table 5). 
422 Statistics of the optimal site matching at the three selected sites using single WTs (2013-2015) ${ }^{\mathrm{a}, \mathrm{b}, \mathrm{c}}$.

\begin{tabular}{|c|c|c|c|c|c|c|}
\hline \multirow[t]{3}{*}{ Parameter } & \multicolumn{6}{|l|}{ Site } \\
\hline & \multicolumn{2}{|c|}{ Cabauw } & \multicolumn{2}{|l|}{ Boulder } & \multicolumn{2}{|l|}{ FINO3 } \\
\hline & Mean & Range & Mean & Range & Mean & Range \\
\hline \multicolumn{7}{|l|}{ Site characteristics } \\
\hline$z(\mathrm{~m})$ & & $10-160$ & & $10-160$ & & $50-150$ \\
\hline$\alpha$ & 0.243 & $0.203-0.267$ & 0.106 & $0.100-0.133$ & 0.098 & $0.041-0.124$ \\
\hline$v_{m}(\mathrm{~m} / \mathrm{s})$ & 6.76 & $4.24-8.15$ & 4.70 & $3.61-5.21$ & 10.36 & $9.71-10.98$ \\
\hline$v_{\text {median }}(\mathrm{m} / \mathrm{s})$ & 6.50 & $3.76-7.95$ & 3.69 & $2.78-4.09$ & 10.17 & $9.49-10.83$ \\
\hline$v_{m p}(\mathrm{~m} / \mathrm{s})$ & 6.08 & $3.44-7.21$ & 3.19 & $2.69-3.29$ & 9.02 & $8.61-9.32$ \\
\hline$v_{m e}(\mathrm{~m} / \mathrm{s})$ & 9.76 & $6.54-12.01$ & 7.82 & $5.71-9.04$ & 15.15 & $13.84-16.52$ \\
\hline$c(\mathrm{~m} / \mathrm{s})$ & 7.60 & $4.72-9.19$ & 5.10 & $3.94-5.64$ & 11.65 & $10.94-12.26$ \\
\hline$k$ & 2.41 & $2.07-2.51$ & 1.78 & $1.67-1.92$ & 2.26 & $2.14-2.37$ \\
\hline$\rho\left(\mathrm{kg} / \mathrm{m}^{3}\right)$ & 1.235 & $1.224-1.246$ & 0.991 & $0.982-1.001$ & 1.235 & $1.233-1.240$ \\
\hline$P\left(\mathrm{~W} / \mathrm{m}^{2}\right)$ & 344.3 & $102.9-558.1$ & 177.9 & $80.7-243.1$ & 1103.5 & $871.1-1384.3$ \\
\hline \multicolumn{7}{|l|}{ WT design parameters } \\
\hline$H_{\text {hub }}(\mathrm{m})$ & & $10-160$ & & $10-160$ & & $50-150$ \\
\hline$P_{r}(\mathrm{~kW})$ & 1479 & $1-3400$ & 1512 & $1.5-3500$ & 3731 & $2000-8000$ \\
\hline$D(\mathrm{~m})$ & 76 & $3-131$ & 80 & $3.2-131$ & 109 & $80-164$ \\
\hline$\Phi=v_{r} / v_{i}$ & 4.328 & $2.250-7.500$ & 4.368 & $2.250-7.500$ & 3.914 & $3.500-5.000$ \\
\hline$\eta_{r}=P_{r} /\left[(1 / 2) \rho A v_{r}^{3}\right]$ & 0.251 & $0.101-0.412$ & 0.232 & $0.101-0.395$ & 0.251 & $0.159-0.367$ \\
\hline \multicolumn{7}{|l|}{ Paired parameters } \\
\hline$\beta=v_{m} / v_{i}$ & 2.537 & $1.103-4.054$ & 1.723 & $1.008-2.654$ & 2.986 & $2.427-4.250$ \\
\hline$v_{r} / c$ & 1.701 & $1.193-2.608$ & 2.345 & $1.656-3.313$ & 1.205 & $0.997-1.497$ \\
\hline$\eta_{T}=A E Y / E_{a}$ & 0.251 & $0.160-0.371$ & 0.185 & $0.114-0.230$ & 0.183 & $0.145-0.219$ \\
\hline
\end{tabular}

Energy output and cost parameters

\begin{tabular}{lllllll}
\hline$A_{W T}(\%)$ & 99.38 & $98-60-99.90$ & 99.36 & $98-60-99.90$ & 98.82 & $98.60-99.90$ \\
$C F(\%)$ & 35.52 & $13.34-53.67$ & 14.59 & $5.00-20.94$ & 51.83 & $44.60-57.80$ \\
$L C o E(\$ / M W h)$ & 232 & $58-4869$ & 514 & $163-7995$ & 109 & $95-158$ \\
\hline
\end{tabular}

${ }^{\mathrm{a}}$ Vertical profiles are based on 26,280 1-h records over the period 01/01/2013-31/12/2015.

424 bo. processed WTs: 377 (Cabauw and Boulder); 23 (FINO3).

$425{ }^{\mathrm{c}}$ Values of WT design, paired, energy output and cost parameters refer to energy yield computations 426 performed for the two $z$-varying lists of candidate WTs retrieving minLCoE and maxCF. 


\section{Table 5}

429 WTs performing the optimal site matching by optimization condition at the three selected sites $430 \quad(2013-2015)^{\mathrm{a}, \mathrm{b}}$.

\begin{tabular}{|c|c|c|c|c|c|c|c|c|}
\hline \multirow[t]{2}{*}{ Site } & \multicolumn{2}{|c|}{ Optimization } & \multirow[t]{2}{*}{ WT model } & \multirow{2}{*}{$\begin{array}{l}H_{\text {hub }} \\
\text { (m) }\end{array}$} & \multirow{2}{*}{$\begin{array}{l}P_{r} \\
(\mathrm{~kW})\end{array}$} & \multirow{2}{*}{$\begin{array}{l}D \\
(\mathrm{~m})\end{array}$} & \multirow{2}{*}{$\begin{array}{l}v_{i} \\
(\mathrm{~m} / \mathrm{s})\end{array}$} & \multirow{2}{*}{$\begin{array}{l}v_{r} \\
(\mathrm{~m} / \mathrm{s})\end{array}$} \\
\hline & condition & score & & & & & & \\
\hline \multicolumn{9}{|c|}{ Cabauw } \\
\hline & MinLCoE & $58 \$ / \mathrm{MWh}$ & VENSYS 82-1500 & 100 & 1500 & 82.3 & 3.0 & 12 \\
\hline & $\mathrm{MaxCF}$ & $53.67 \%$ & W2E HARVESTER 2.0 & 140 & 2000 & 116 & 3.5 & 10 \\
\hline \multicolumn{9}{|c|}{ Boulder } \\
\hline & MinLCoE & 163 \$/MWh & LEITWIND LTW77-800 & 80 & 800 & 76.7 & 3.0 & 11 \\
\hline & $\mathrm{MaxCF}$ & $20.94 \%$ & W2E HARVESTER 2.0 & 140 & 2000 & 116 & 3.5 & 10 \\
\hline \multicolumn{9}{|c|}{ FINO3 } \\
\hline & MinLCoE & $95 \$ / M W h$ & NORDEX N90-2500 & 80 & 2500 & 90 & 3.5 & 14 \\
\hline & $\mathrm{MaxCF}$ & $57.80 \%$ & SIEMENS SWT-2.3-101 & 100 & 2300 & 101 & 3.5 & 12 \\
\hline
\end{tabular}

${ }^{\mathrm{a}}$ Vertical profiles are based on 26,280 1-h records over the period 01/01/2013-31/12/2015.

${ }^{\mathrm{b}}$ No. processed WTs: 377 (Cabauw and Boulder); 23 (FINO3).

\subsection{Cabauw}

According to the European wind resource atlas [59] over "open plain" sites, Cabauw can be classified as a medium site, as at $50 \mathrm{~m} v_{m}$ is equal to $6.1 \mathrm{~m} / \mathrm{s}$ and $P$ to $242 \mathrm{~W} / \mathrm{m}^{2}$. Since relying on a 213-m tall met mast with densely installed sensors up to $200 \mathrm{~m}$ (Table 2), profiles at intermediate heights are well approximated all over the 10-160 m height range; valid data percentage is also remarkable (98.08\%). With annual average $\alpha$ values ranging $0.203-0.267$, the site exhibits a significantly pronounced vertical profile of both $v_{m}$ and particularly $P$ (Fig. 4a). Interestingly, $k$ vertical profile increases from $2.07(10 \mathrm{~m})$ to a maximum of $2.51(50-70 \mathrm{~m})$, and then decreases above to 2.32: this Cabauw $k$ profile is similar to the one found by Justus et al. [31] at four tower sites in US, increasing with height up to a maximum at 60-70 m; conversely, this $k$ outcome contrasts with Chang et al. [2], who stated that "the shape parameter is independent of WT hub height". As a result, the shape of wind speed Weibull distribution at Cabauw exhibits a substantial 446 height variation (Fig. 3a). 
Pairing all available onshore WTs to the Cabauw's wind resource characteristics across the full 10-160 m height range resulted in the statistics summarized in Table 4, where for overall WT energy losses a 10.07-12.33\% range was considered (Table 3). A very wide range of WT design parameters (e.g. $P_{r}$ of $1-3400 \mathrm{~kW}$, and $D$ of 3-131 m), and resulting performance parameters (e.g. $C F$ of $13.34-53.67 \%$, and $L C o E$ of 58-4869 $\$ / \mathrm{MWh}$ ) was observed in selecting WTs satisfying both optimization criteria. Height variations of minLCoE and maxCF are quite different (Fig. 4b): while maxCF quite regularly increases according to an exponential-like shape, minLCoE decreases dramatically up to about $25 \mathrm{~m}$, smoother up to $70-80 \mathrm{~m}$, then basically remains unchanged at heights above. The irregular pattern exhibited by these vertical profiles is due to the nonhomogeneous distribution of available WTs characteristics (Fig. 1), as also shown by Carrillo et al. [9]: both objective functions are thus not continuous and derivable functions.

In Table 5 details of WT optimal site matching, sorted by optimization condition, are shown. The minLCoE condition (58 \$/MWh) is satisfied by using the $1500-\mathrm{kW}$ VENSYS 82 WT with $H_{h u b}=100$ $\mathrm{m}$, while the maxCF condition (53.67\%) is achieved by using the 2000-kW W2E HARVESTER with $H_{h u b}=140 \mathrm{~m}$. This highlights that the search for WT site optimization is primarily a search for the optimum $H_{h u b}$. Furthermore, minLCoE is not achieved by indefinitely increasing $H_{h u b}$, but rather through detection of an "optimum" $H_{h u b}$ obtained as a unique solution of the optimization procedure. This outcome is consistent with findings by Ashuri et al. [20]: since WT tower has the highest cost trend exponent, the extra energy captured by larger WTs (upscaling) does not compensate for the higher $C_{\text {initial }}$, and thus $L C o E$. The power curves of optimal WTs and corresponding wind speed Weibull distributions are shown in Fig. 3a.

Within a survey worldwide updated to the year 2014, IEA-ETSAP and IRENA [43] reported typical values of $L C o E$ ranging $60-120 \$ / \mathrm{MWh}$ for onshore and 100-210 \$/MWh for offshore projects. Therefore, with $L C o E=58 \$ / \mathrm{MWh}$ Cabauw is definitely a potential site for an economic viable wind energy project. As a comparison, this Cabauw optimization returned an LCoE slightly 
$473 \mathrm{~kW}$ WTs at three onshore sites in Iran, which at $40 \mathrm{~m}$ AGL were affected, however, by $v_{m}$ values $474(8.91-10.5 \mathrm{~m} / \mathrm{s})$ remarkably higher than the one at Cabauw $(5.74 \mathrm{~m} / \mathrm{s})$. 

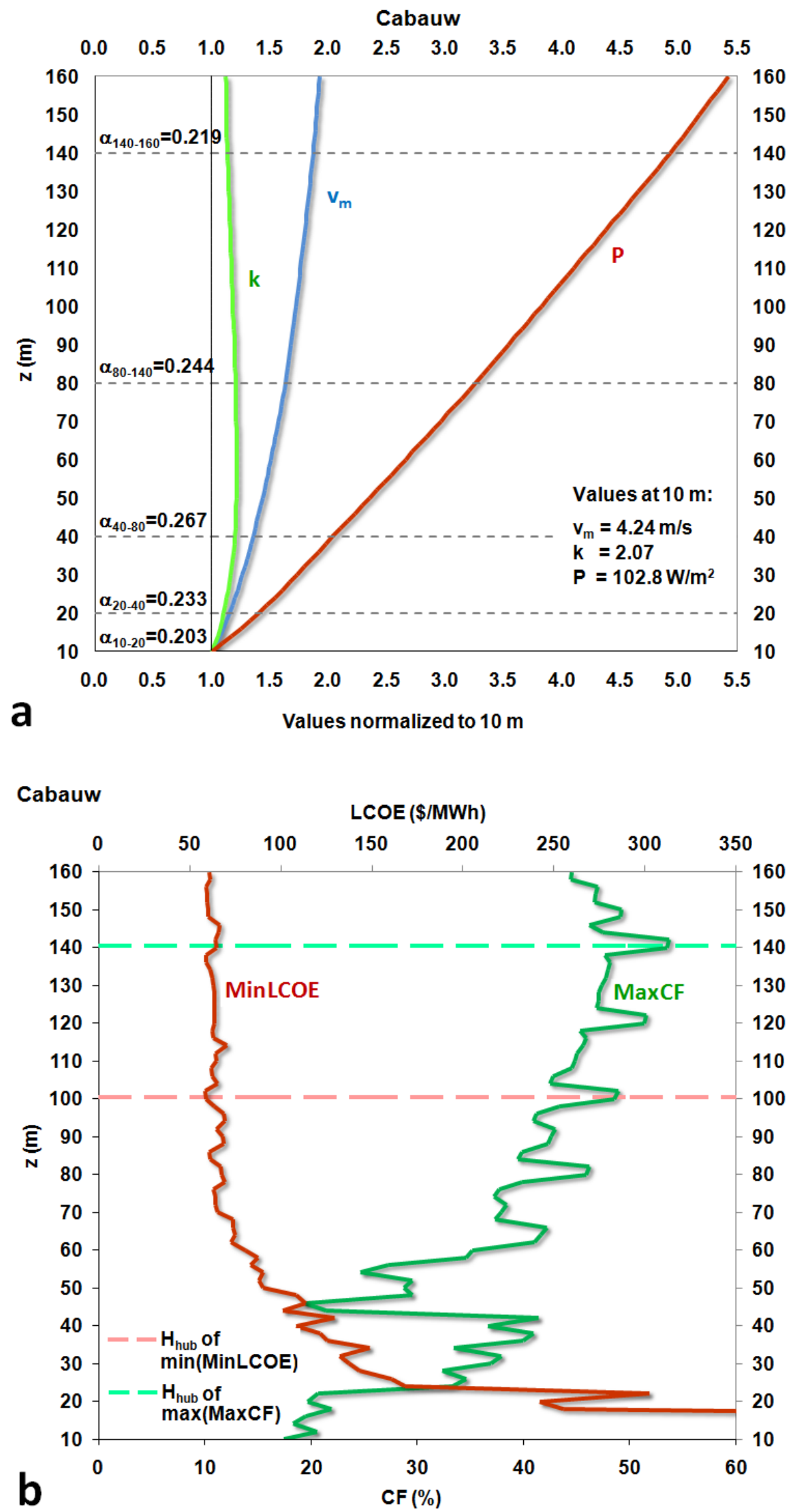

477 Fig. 4. Annual average vertical profiles (10-160 m) observed 2013-2015 at Cabauw of: (a) site's 478 characteristics $\left(v_{m}, k\right.$ and $P$ ); (b) minLCoE and maxCF using 377 WTs. Dashed lines denote $H_{h u b}$ of the two WTs (see Table 5) achieving minLCoE (red) and maxCF (green) over the full height range. 


\subsection{Boulder}

With $50-\mathrm{m} v_{m}$ of $4.5 \mathrm{~m} / \mathrm{s}$ and $P$ of $153 \mathrm{~W} / \mathrm{m}^{2}$, Boulder would be classified as a "poor" (or "class 1") site based on the NREL wind power classification (http://www.nrel.gov/gis/wind_detail.html). Though the valid data percentage is remarkable $(98.95 \%)$, vertical profiles above $80 \mathrm{~m}$ are affected by a certain degree of approximation (Table 2). Compared to Cabauw, Boulder exhibits lower annual average $\alpha$ values, steadily decreasing with height (0.133 to 0.100$)$, which result in smoother vertical profiles of both $v_{m}$ and $P$ (Fig. 5a). Also, different from Cabauw, the $k$ vertical profile steadily decreases with height (1.92 to 1.67). In applying all available onshore WTs to Boulder (Table 4) an 11.93-14.14\% range of overall WT energy losses was accounted (Table 3). A wide range of WT design, energy output and cost parameters was again observed in seeking WTs achieving minLCoE and maxCF per height.

Vertical profiles of minLCoE and maxCF are quite similar to those at Cabauw (Fig. 5b). However, a closer analysis reveals that the overall minLCoE vertical gradient is lower, and that in minLCoE pattern there is no transition between a dramatic (up to $60 \mathrm{~m}$ ) and basically negligible decrease at heights above. Furthermore, from a certain height (about 45-50 m) upwards minLCoE and maxCF exhibit an almost mirrored contrasting pattern $(\mathrm{r}=-0.797)$. Interestingly, as for the maxCF condition, Boulder is best suited by using the same WT and same $H_{h u b}$ as at Cabauw (Table 5), while the minLCoE condition is met by using the 800-kW LEITWIND LTW77 WT with $H_{h u b}=80 \mathrm{~m}$; however, far higher minLCoE $(163 \$ / \mathrm{MWh})$ and lower maxCF $(20.94 \%)$ are achieved herein. It should be noted that, as at Cabauw, the minLCoE condition is met at Boulder at lower heights than the maxCF condition. The outcome from both these onshore locations is consistent with findings by Mirghaed and Roshandel [19] that, for each site, a specific optimal configuration and size would minimize $L C o E$.

On the other hand, based on the typical $L C o E$ values reported above for onshore sites (60-120 \$/MWh), with $L C o E=163 \$ / \mathrm{MWh}$ Boulder is a site where the installation of a wind farm in the area would not be economically viable. 


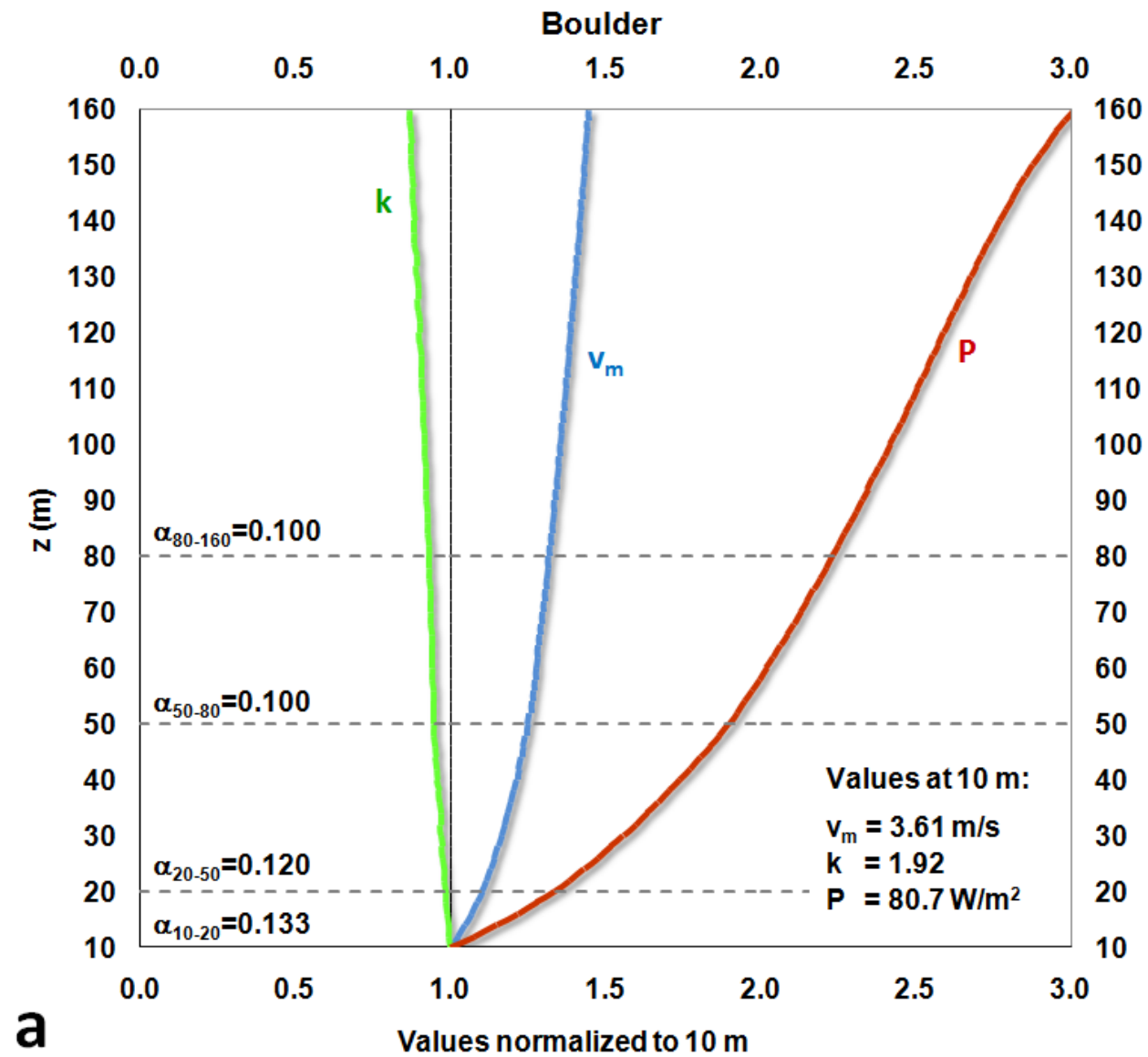

506

\section{Boulder} LCOE ( $\$ / M W h)$

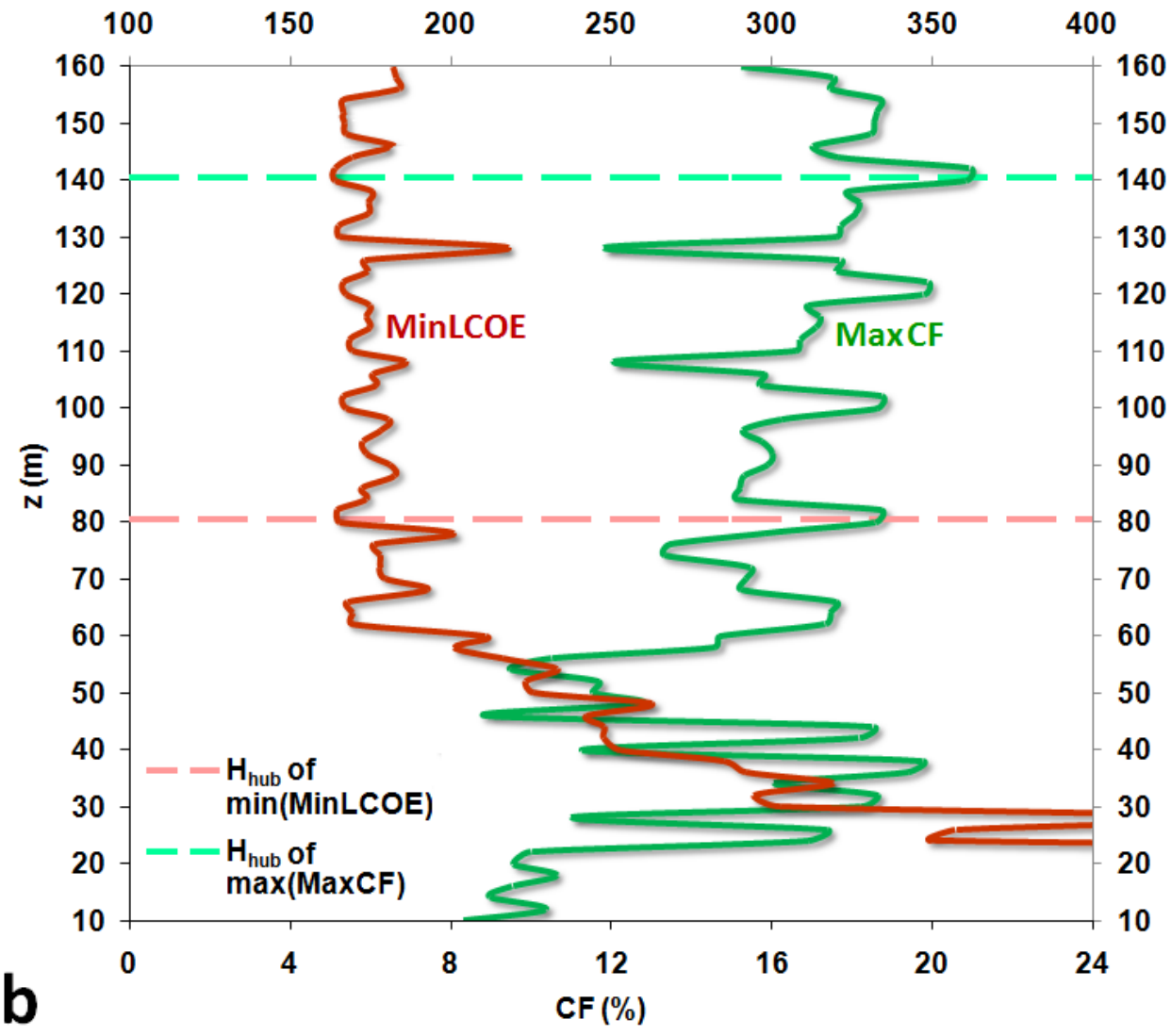

508 Fig. 5. Same as Fig. 4, but at Boulder. 
Since affected by $50-\mathrm{m} v_{m}$ equal to $9.7 \mathrm{~m} / \mathrm{s}$ and $P$ to $871 \mathrm{~W} / \mathrm{m}^{2}$, FINO3 can be defined as a “superb" (maximum class) "open-sea" site [59].

The valid data percentage $(82.49 \%)$ is lower than onshore (Table 2); also, vertical profiles above 95-100 m are affected by a certain approximation. FINO3 annual average $\alpha$ values are lower than onshore, generally increasing with height $(0.041$ to 0.110$)$, barring $60-70 \mathrm{~m} . P$ and particularly $v_{m}$ vary very slightly with height: the small overall excursions of $v_{m}(13 \%)$ and $\rho(0.6 \%)$ result in a similarly quite smooth $P$ vertical profile (Fig. 6a). As at Boulder, the $k$ vertical profile decreases with height (2.37 to 2.14). Also, at FINO3 wind speed Weibull distributions do not appreciably vary with height (Fig. 3c).

With respect to the onshore sites, owing to the far smaller number of available WTs with not particularly uniformly distributed WT characteristics (Fig. 1), along with not particularly wide $P$ vertical variation (Fig. 6a), WT application to FINO3 across the full 50-150 $\mathrm{m}$ height range returned substantially different statistics (Table 4). The preliminary search for WTs achieving minLCoE and maxCF at any given height, accounting for a 10.98-13.22\% overall energy losses (Table 3), was performed by employing design parameters of $P_{r}$ ranging 2000-8000 kW, and $D$ ranging 80-164 m. Unlike at both onshore locations, at FINO3 the overall range of both $C F$ (44.60$57.80 \%)$ and $L C o E(95-158 \$ / \mathrm{MWh})$ is very narrow (Table 4). Furthermore, vertical profiles of minLCoE and maxCF are neither contrasting nor almost-mirrored as at the onshore sites: $C F$ weakly increases exhibiting a "paunchy" pattern 75-130 m, while $L C o E$ decreases slightly up to 85 $\mathrm{m}$, and then increases slightly at higher heights (Fig. 6b).

Also at the offshore location the two performance conditions are satisfied by using different WTs and different $H_{h u b}$ values: minLCoE (95 \$/MWh) is achieved by using the 2500-kW NORDEX N90 WT with $H_{h u b}=80 \mathrm{~m}$, while maxCF $(57.80 \%)$ by using the $2300-\mathrm{kW}$ SIEMENS SWT-101 WT with $H_{h u b}=100 \mathrm{~m}$. Furthermore, as at both onshore locations, also at FINO3 the minLCoE condition is met at lower heights than the maxCF condition. 
In any case, at FINO3 there is no need to go too high with wind energy capture, as even at the 536 lowest $H_{h u b}$ of available offshore WTs $(50-60 \mathrm{~m}$, Fig. 1a) the site proves to offer prospects for 537 profitable energy projects.

538 Summarizing, based on the typical $L C o E$ range reported above for offshore sites (100-210 $539 \$ / \mathrm{MWh}$ ), with $L C o E=95 \$ / \mathrm{MWh}$ a wind farm project at FINO3 might be economically attractive. 540 However, because of the higher uncertainty affecting the $C_{\text {initial }}$ computation through Eq. (23) at 541 offshore locations, this $L C o E$ should actually be taken as a mere indicative amount, particularly 542 while considering the site is located $80 \mathrm{~km}$ off the coast, and therefore the costs for the balance of 543 system would likely be higher than the currently considered $52 \%$ rough estimate. 

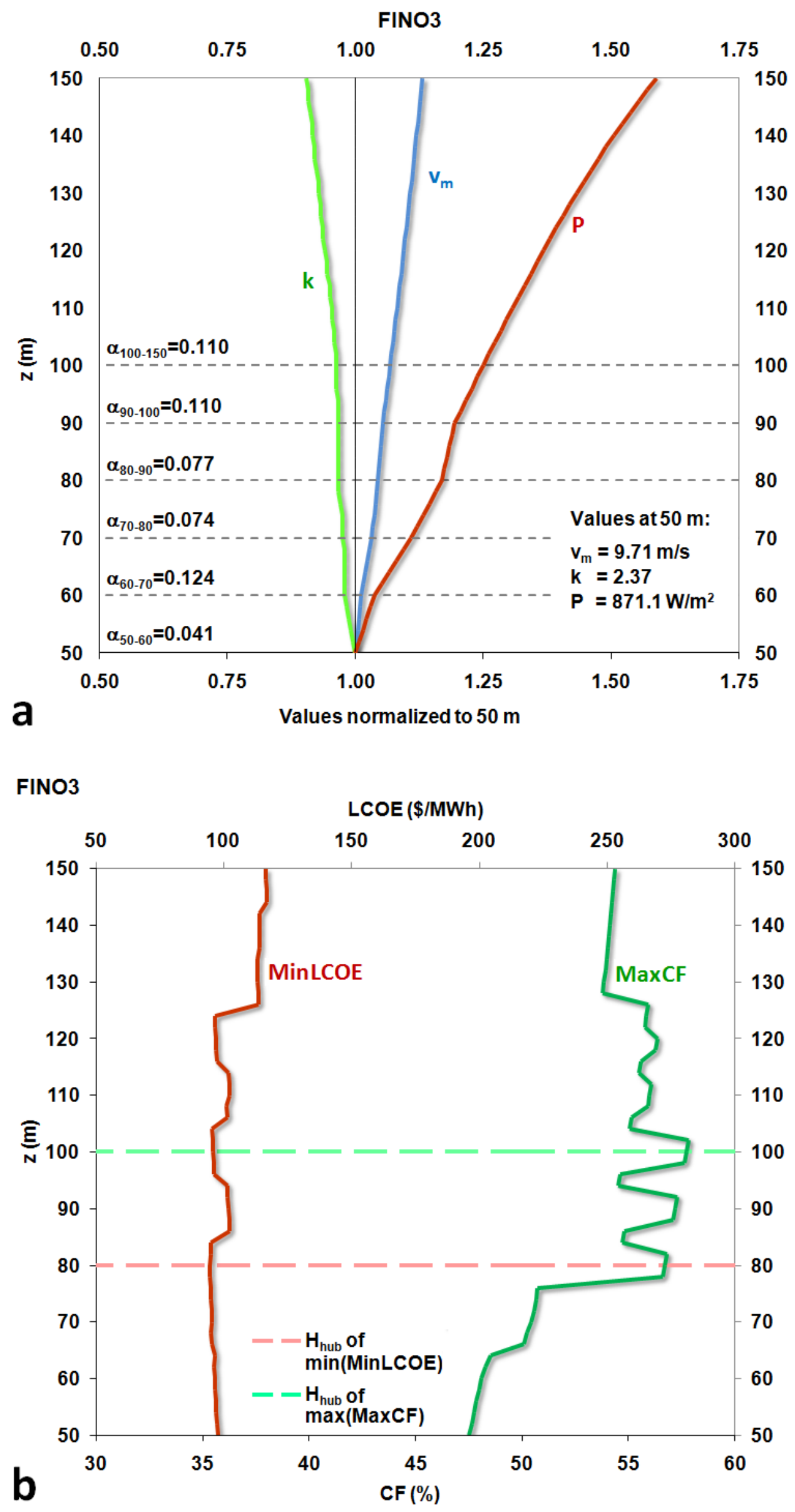

547 Fig. 6. Same as Fig. 4, but at FINO3, with vertical profiles between 50 and 150 m, and using 23 WTs. 


\section{Improving site optimization through the SOMs}

\subsection{SOM settings}

The SOM algorithm was applied to the annual average vertical profiles of the following variables: $k, P, P_{r}, D, \Phi, \eta_{r}, \eta_{T}, \beta, v_{r} / c, A_{W T}, C F$, and $L C o E$. This dataset includes those values, varying by $z$ steps, obtained during phases (ii) and (iii) of the optimization procedure $(\S 5.1)$. The

SOMs for each location were visualized by component planes represented by the above-selected variables. To avoid redundancy, those variables with vertical patterns strictly correlated to each other were withdrawn, such as $v_{m}$ and $H_{h u b}$, both strongly correlated to $P: v_{m}$ by $r=0.982-0.995$, and $H_{h u b}$ by $r=0.981-0.999$. Therefore, the SOM component plane of $P$ should be considered the same as $v_{m}$ and $H_{h u b}$.

SOM training, conducted according to the Kohonen's algorithm [47], was performed using 20,000 iterations (more than 500 times the number of lattice neurons), and initial values of 0.9 (close to 1) for the learning rate and 5 units (more than half the lattice's diameter) for the neighbourhood radius. The Mexican hat neighbourhood function, proposed by Kohonen [49], was employed as returning a wider (more reliable) variables' variation range than the most commonly used Gaussian function. For evaluating the goodness of SOM, the error measure proposed by Kaski and Lagus [60], which combines quantization and topographic errors, was adopted. consisting of a number of neurons corresponding to the 2013-2015 annual average vertical profiles of the above-selected variables; (ii) an output layer, consisting of 36 neurons, visualized by 569 hexagons, organized in two-dimensional grids with 6 rows and 6 columns. Thus, the number of trained neurons in the output layer (36) accounted for $2 \%$ of the neurons of the input layer (1800). All SOM computations were performed using Living for SOM (v. 1.4.4), an open-source tool freely available at: http://livingforsom.com. 
The results of the SOM application are presented in Fig. 7 (Cabauw), Fig. 8 (Boulder), and Fig. 9 (FINO3). For an easier SOM analysis, a key is provided in these figures: both hexagons corresponding to minLCoE and maxCF neurons are highlighted, as well as their related values and distribution percentile ranks for each component plane are shown.

\subsection{Cabauw}

At Cabauw (Fig. 7), the neuron corresponding to the minLCoE condition (72 \$/MWh) matches with the one corresponding to the maxCF condition $(37.71 \%)$. Therefore, contrary to the previous vertical profile analysis $(\S 5.2)$, the SOMs are capable of recognising that these two optimization conditions are not apart, but belong to the same neuron, thus suggesting that one choice is equivalent to the other: this implies that selecting the WT with the lower $H_{h u b}$, out of the two detected in Table 5, is likely the most economically viable solution. This minLCoE $=$ maxCF neuron (hexagons highlighted in light blue, with an occurrence of 17.2\%) is associated to maxima of site's characteristics $(P)$, WT design parameters $\left(P_{r}, D, \Phi\right.$ and $\left.\eta_{r}\right)$, paired parameters $(\beta)$, as well as to minima of a paired parameter as $v_{r} / c$. Conversely, the role of $\eta_{T}$, associated by the $20^{\text {th }}$ percentile of its distribution, is secondary: as also observed by Chang et al. [10] at four onshore coastal locations in Taiwan, $\eta_{T}$ cannot be taken as a reliable energy yield indicator.

A closer SOM analysis, focused on the whole lattice topology of each component plane rather than single neurons, reveals that the topology patterns of $C F$ and $L C o E$ are almost perfectly mirrored, thus suggesting that at Cabauw pursuing either minLCoE or maxCF over their entire dataset leads to the same result. Furthermore, the $C F$ topology exhibits the same min-to-max orientation (BL-to-TL) as $P, P_{r}$ and $D$, which confirms that increasing WT design parameters such as $P_{r}$ and $D$ results in a general $C F$ increase (and thus $L C o E$ decrease). A similar SOM topology is exhibited by $\beta$ (min-to-max) and $v_{r} / c$ (max-to-min). Compared to $C F$ and $L C o E$, SOM topology for $\eta_{T}$ and $A_{W T}$ is different, as their min-to-max $\left(\eta_{T}\right)$ and max-to-min $\left(A_{W T}\right)$ orientation, which is quite mirrored, is BL-to-TR. Also SOM topology for $k$ differs from both $C F$ and $L C o E$. Therefore, since 
poorly associated to $k$, at Cabauw $C F$ is quite insensitive to the shape of wind speed Weibull 600 distribution (Fig. 3a): this score is consistent with the $C F-k$ curves by $\beta$ and $\Phi$ plotted by 601 Pallabazzer [6], indicating that the effect of $k$ on $C F$ can be neglected for currently achieved values of $\beta$ and $\Phi$.

603

604

\subsection{Boulder}

605

Similarly to Cabauw, at Boulder (Fig. 8) the two conditions of minLCoE (207 \$/MWh) and 606 $\operatorname{maxCF}(12.66 \%)$ match. This minLCoE $=$ maxCF common neuron (hexagons highlighted in light blue, with an occurrence of $17.4 \%$ ) is associated to maxima of $P, P_{r}, D, \Phi$, and $\beta$, and to minima of $k$ and $v_{r} / c$; in addition to the Cabauw SOM scenario, this neuron is also associated to the highest $\eta_{T}$.

However, the SOM analysis performed by considering the whole lattice topology reveals that, unlike at Cabauw, at Boulder the patterns of $C F$ and $L C o E$ are not mirrored, as min-to-max $C F$ orientation is TL-to-BR, while $L C o E$ does not exhibit a monotonic pattern since affected by two local minima. Actually, $L C o E$ topology pattern is quite similar to $P, P_{r}, D$, and $\eta_{T}$; conversely, minto-max $C F$ orientation is quite similar to orientations of $\beta$ (min-to-max) and $v_{r} / c$ (max-to-min). This outcome suggests that a different parameters setting may either result in an $L C o E$ reduction or $C F$ increase, but not both conditions at the same time: in terms of WT design parameters, for example, increasing $P_{r}$ and $D$ implies a direct $L C O E$ reduction. Furthermore, confirming findings by Pallabazzer [6], increasing $\beta$ results in a $C F$ increase; as at Cabauw, SOM topology pattern of $C F$ is also significantly anti-correlated to $v_{r} / c(r=-0.733)$.

Summarizing, outcomes from Boulder are consistent with those returned by Fuglsang et al. [5], who suggested that increasing $D$ and $H_{h u b}$ increases annual energy yield. However, as noted by Maki et al. [18] and Ashuri et al. [20], at some point the increase in annual energy yield is not sufficient to outweigh the increase in $L C o E$, such as optimum values of both $H_{h u b}$ and $D$ shall be detected which correspond to local minima for $L C o E$. 
A substantially different SOM scenario than at the onshore sites can be observed at FINO3 (Fig. 9), where minLCoE neuron (102.3 $\$ / \mathrm{MWh}$, with an occurrence of $6.7 \%)$, is associated to the $45^{\text {th }}$ percentile of the $C F$ distribution, while maxCF neuron $(52.97 \%, 12.8 \%$ of events) is associated to maximux $L C o E$ neuron. However, as described in $\S 5.4$, this SOM scenario is likely due to the very narrow range of both $L C o E$ and $C F$ component planes, which results from the small number of processed WTs as well as a fairly slim $P$ vertical variation.

At FINO3, $C F$ topology exhibits a clear similarity with $P, P_{r}$, and $D$, as well as (mirrored) with $\eta_{T}$, and $v_{r} / c$, thus suggesting that maxCF should be pursued by increasing WT size, or by decreasing $\eta_{T}$ or $v_{r} / c$. Conversely, $L C o E$ topology is quite similar (though with the same orientation) with $P_{r}$ and $D$, and to a lesser extent with $P$ (and thus $H_{h u b}$ ), meaning that $H_{h u b}$ plays a minor role herein: since FINO3 is a strongly energetic site even at the lowest $H_{h u b}$ of available offshore WTs (50-60 $\mathrm{m}$ ), these results confirm that to minimize $L C o E$ it is pointless going too high with wind resource capture. Furthermore, although not exactly similar to $L C o E$ max-to-min orientation, $A_{W T}$ min-tomax orientation suggests that availability is a key factor to minimize $L C o E$ at FINO3. With a SOM topology mirrored vs. $C F$ and significantly dissimilar vs. $L C o E$, at FINO3 $k$ pattern is even more different from $C F$ and $L C o E$ than onshore, thus indicating that its role is minor. cannot be concurrently satisfied: at FINO3 $L C o E$ cannot be minimized by increasing WT design parameters such as $P_{r}$ or $D$. This outcome contrasts with both offshore findings by Snel [45] that a larger diameter with more annual energy yield becomes economically attractive, and by Fuglsang et 649 al. [5] that $L C o E$ may be primarily reduced through increased annual energy yield from increasing WT diameter. 


\section{Cabauw}
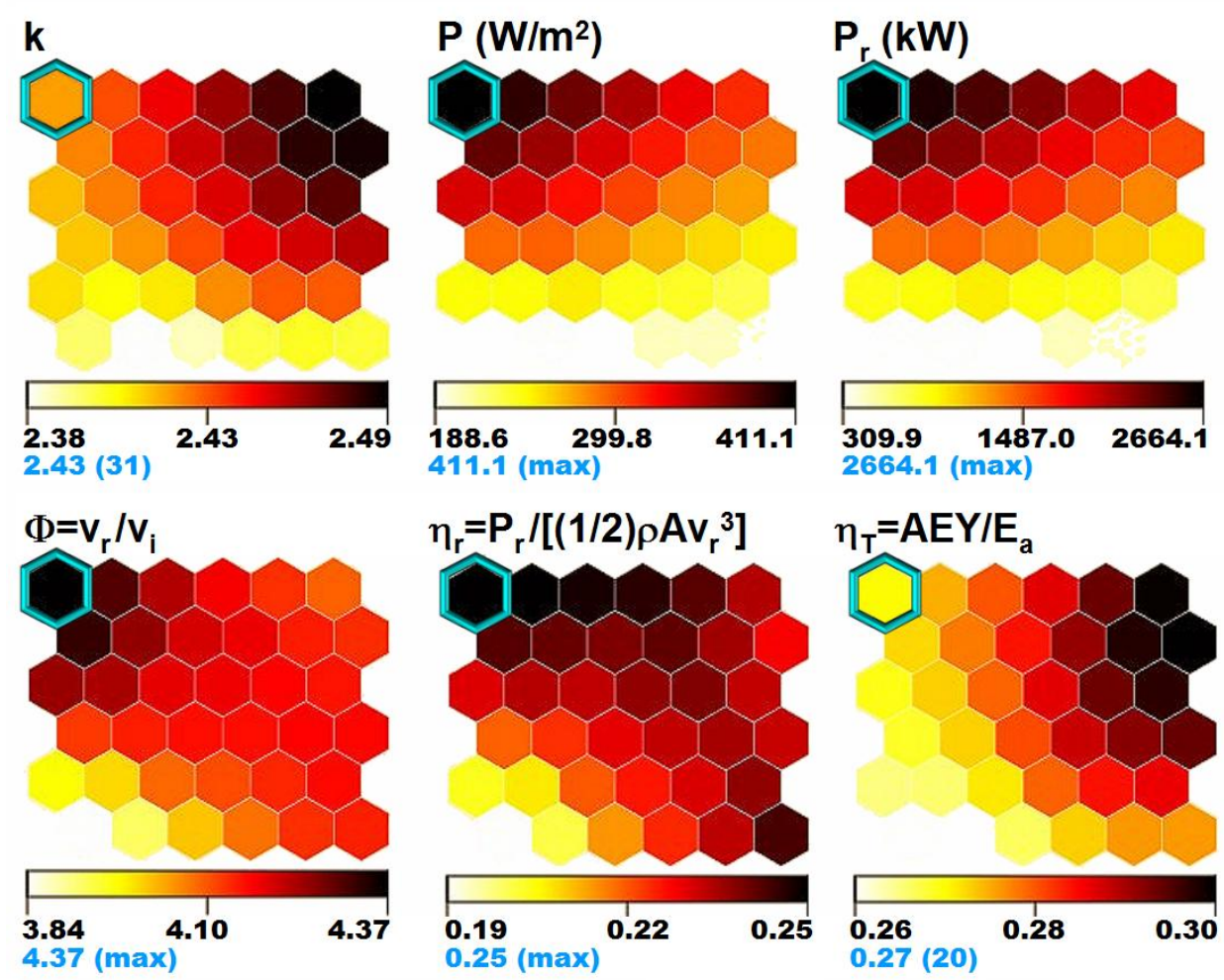

D (m)
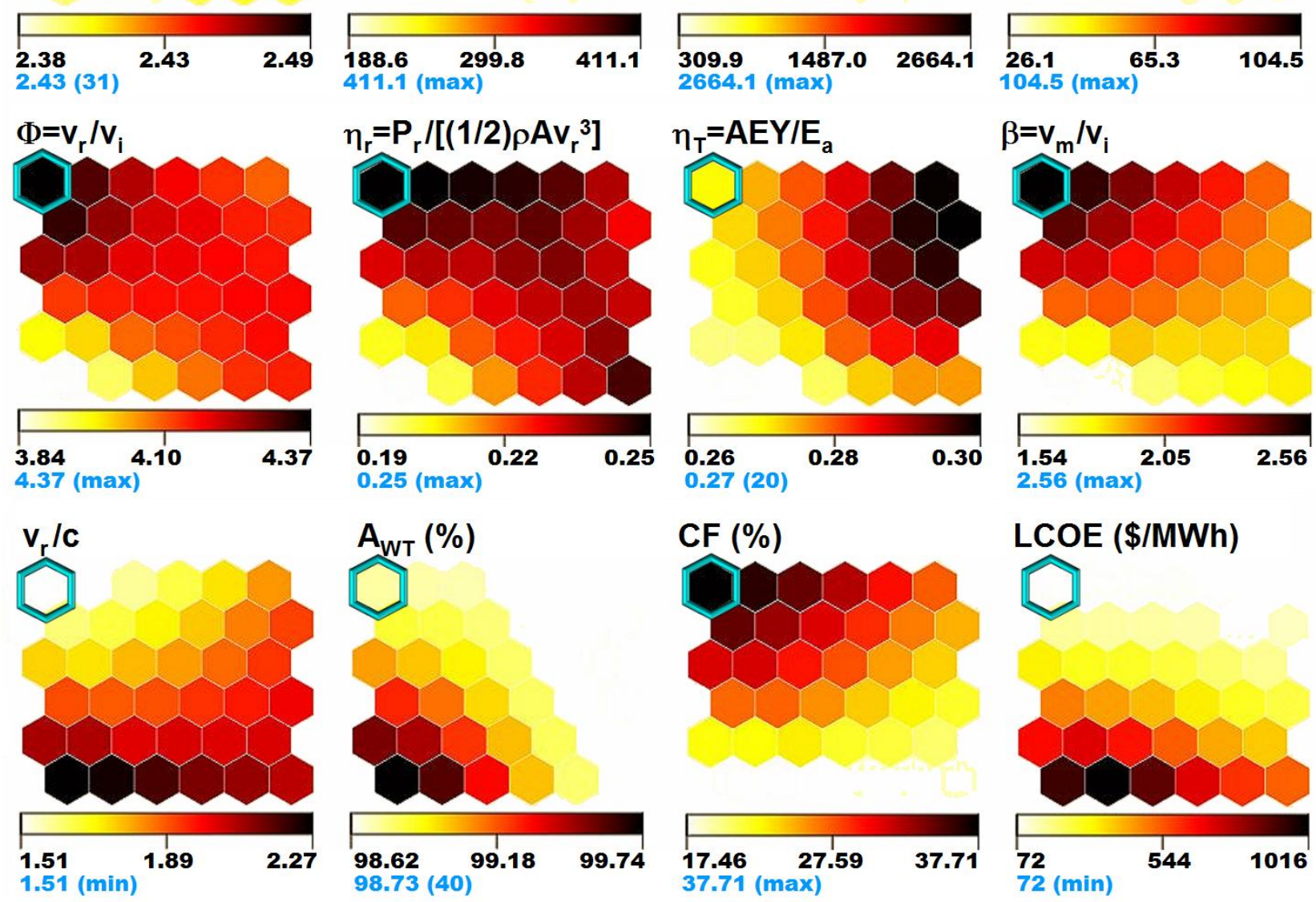
Min. LCOE = Max CF (17.2\% events)

651 Fig. 7. SOM component planes obtained at Cabauw from 2013-2015 annual average vertical profiles (10-160 m) for the following parameters: site $(k$ and $P)$; WT design $\left(P_{r}, D, \Phi\right.$ and $\left.\eta_{r}\right)$; paired $\left(\eta_{T}, \beta\right.$ and $\left.v_{r} / C\right)$; energy output $\left(A_{W T}\right.$ and $\left.C F\right)$; cost $(L C o E)$. A total of 377 WTs were processed. The 12 panels are linked by position so as the hexagons in a certain position correspond to the same map unit. Hexagons highlighted in light blue correspond to the minLCoE neuron (in this case, matching with the maxCF neuron): for each component plane, numerical values (and distribution percentile ranks in brackets) of this minLCoE $=$ maxCF neuron are also reported. 


\section{Boulder}
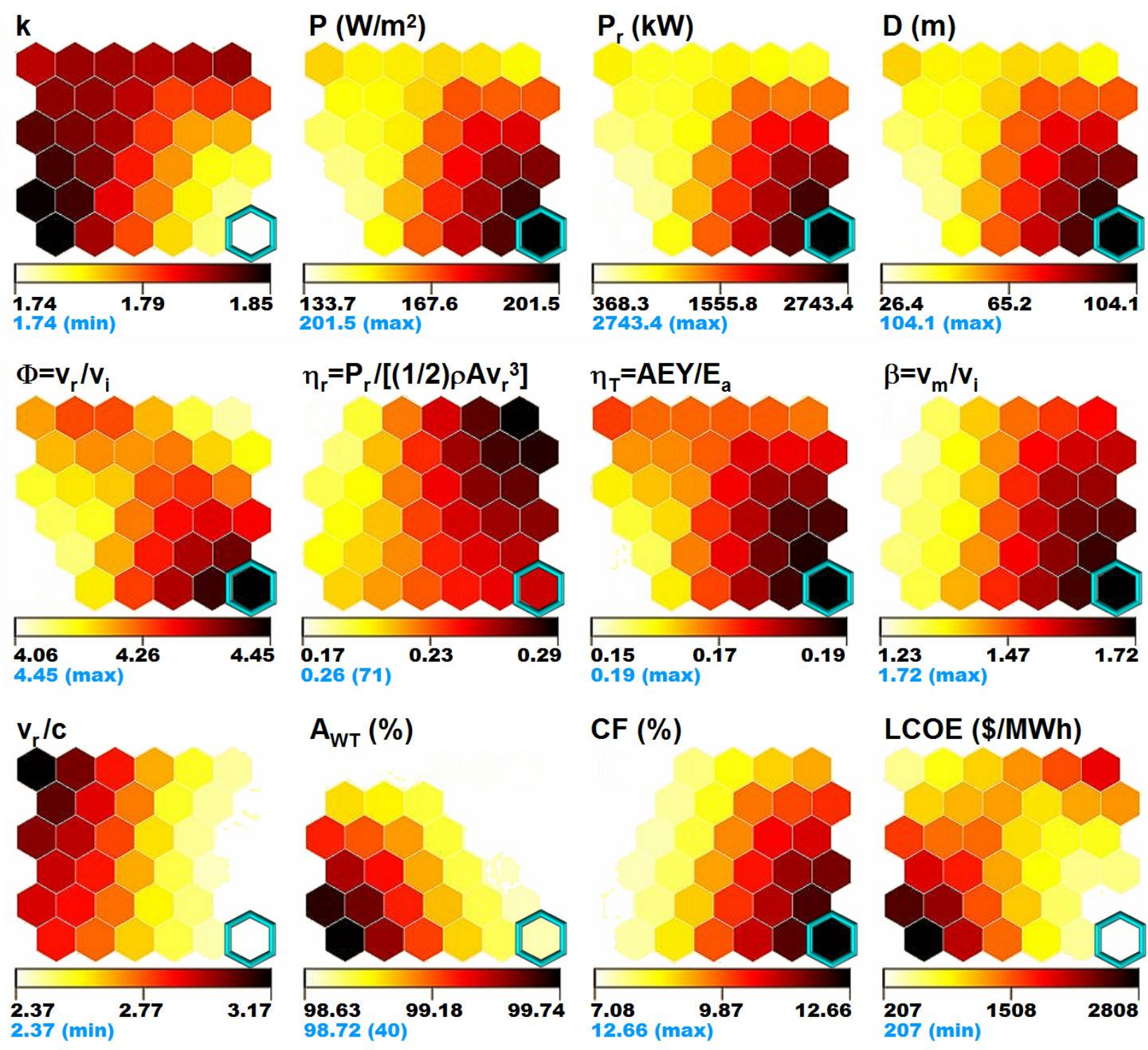

Min. LCOE = Max CF (17.4\% events)

660 Fig. 8. Same as Fig. 7, but at Boulder. Neurons of minLCoE and maxCF are again matching. 


\section{FINO3}
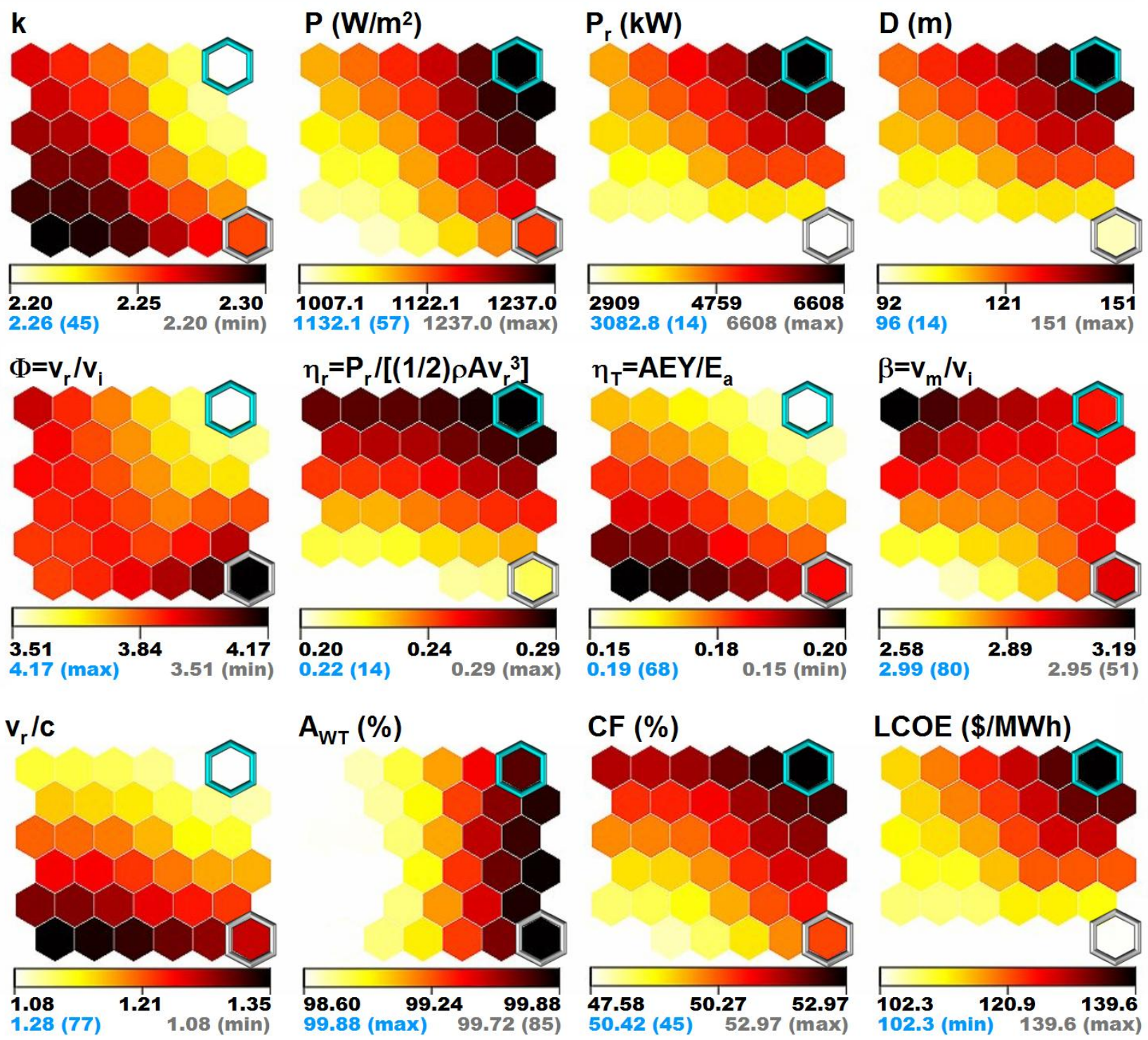

663 Fig. 9. Same as Fig. 7, but at FINO3, with vertical profiles between 50 and $150 \mathrm{~m}$, and processing a

664 total of 23 WTs. Neurons of minLCoE and maxCF are not matching: hexagons highlighted in light 665 blue correspond to the minLCoE neuron, while those highlighted in grey correspond to the maxCF neuron. 


\section{Conclusions}

A WT optimal site matching procedure was developed and applied on two different onshore and one offshore sites, each with a tall met mast installed: (i) Cabauw, a flat and sea-level inland site with medium energy potential; (ii) Boulder, an elevated mountain site with fairly complex terrain and "poor" potential; (iii) FINO3, an offshore platform $80 \mathrm{~km}$ off the coast with "superb" potential. These sites are real case studies approximately belonging to exemplary wind climates as defined in the literature. Sites' characteristics were thoroughly assessed by constructing wind resource vertical profiles based on three years (2013-2015) of 1-h observations collected at mast sensor heights: for each hour, at heights where sensor information was not available variables were vertically interpolated/extrapolated by a step of $2 \mathrm{~m}$. A database of 377 onshore and 23 offshore commercial WTs was used: WT power curves were not fitted, but rather explicitly treated. Two objective functions have been considered: minimizing $L C o E$ and maximizing $C F$.

In addition to detecting the most suitable WT for each site, SOMs were used to provide further insight into those parameters mostly influencing site optimization. A number of approximations have been introduced, as detailed in the following. Only single WTs have been considered, thus neglecting any WT array wake interferences. WT optimization has been pursued by disregarding all site's turbulence issues and WT turbulence regulation compliances. In the $L C o E$ computation, initial capital cost and annual costs have been assessed through a simplified approach based on average statistical values referring to the current US market: this resulted in a higher uncertainty in calculating initial capital cost for the offshore site. A parametric approach was adopted in assessing WT capital cost as an increasing function of $P_{r}, D$ and $H_{h u b}$. For heights above the highest available sensors, $v$ and $T$ profiles have been extrapolated through extension of lower-range profiles. A maximum tolerance $\left( \pm 2 \mathrm{~m}\right.$ onshore and $\pm 5 \mathrm{~m}$ offshore) was taken between $H_{h u b}$ and 692 estimates/observations height. 
As a result, maximizing capacity factor was confirmed to be a good objective function, though not the best, which was minimizing $L C o E$. This study proved that the exact matching of these two optimization conditions (such as at Cabauw) is actually a special case, as in general they do not necessarily match: variously setting WT design and paired parameters may either result in an $L C o E$ reduction or capacity factor increase, but both of these conditions do not occur concurrently. decreasing $L C o E$.

Onshore:

- higher site's energetic potential $(P)$ is of course beneficial, but its pattern is closer associated to LCoE than $C F$;

- minimum $L C o E$ is achieved at lower heights than maximum $C F$;

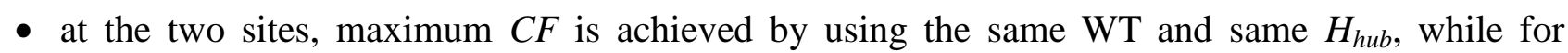
minimizing $L C o E$ two different WTs with different $H_{h u b}$ values were necessary;

- WT availability is not particularly decisive on both $C F$ and $L C o E$;

- the effect of $k$ is somewhat unclear on both $L C o E$ and $C F$;

- $\quad$ among WT design parameters, $P_{r}, D$, and $\Phi$ mostly affect $L C o E$;

- as for paired parameters, $\eta_{T}$ generally impacts on $L C o E$, while $\beta$ and $v_{r} / c$ on $C F$.

710 Offshore:

- the two optimization conditions are clearly not associated;

- the same WT design parameters as onshore $\left(P_{r}\right.$ and $\left.D\right)$ are the most effective on $L C o E$, though 713 they should be minimized to minimize $L C o E$;

714 - $P$ (and thus $H_{h u b}$ ) are not decisive parameters in minimizing $L C o E$ : since FINO3 is a strongly 715 energetic site even at the lowest $H_{h u b}$ of available offshore WTs (50-60 m), to minimize $L C o E$ it 716 is pointless going too high with energy capture;

- as onshore, minimum $L C o E$ is achieved at lower heights than maximum $C F$; 
- the role of $k$ to both $L C o E$ and $C F$ is even less decisive than onshore, as confirmed by the quite height-insensitive wind speed Weibull distributions;

- the same paired parameter as onshore $\left(v_{r} / c\right)$ mostly affects $C F$ : increasing $v_{r} / c$ leads to $C F$ increasing.

Summarizing, this study pointed out that the search for WT site optimization is primarily a search for optimum $H_{h u b}$. One of its key findings is that minimum energy cost may not be achieved by indefinitely increasing $H_{h u b}$, but rather through detection of an optimum value obtained as a unique solution of the optimization procedure: since the WT tower has the highest cost trend exponent, the extra energy captured by larger WTs (upscaling) does not compensate for the higher initial capital cost, and thus $L C o E$. This study also demonstrated that the SOM unsupervised learning ANN-based model greatly improves the "traditional" analysis focussed on the mere variable vertical profiling. SOM capability of recognising the cluster structure of all parameters influencing WT site optimization shed further light on their mutual relationship, thus proving to be an ideal tool to address the non-convex nature of this crucial issue.

\section{Acknowledgements}

The Author wishes to thank all institutions which kindly made available all data used in the work, namely: the National Wind Technology Center (NWTC, http://www.nrel.gov/midc/nwtc_m2), managed by the National Renewable Energy Laboratory (NREL) for the US Department of Energy, for the M2 mast; the Cabauw Experimental Site for Atmospheric Research (CESAR, http://www.cesar-database.nl), managed by the Royal Netherlands Meteorological Institute (KNMI), for the Cabauw mast; the BMWi (Bundesministerium fuer Wirtschaft und Energie, Federal Ministry for Economic Affairs and Energy) and the PTJ (Projekttraeger Juelich, project executing organisation) for the FINO3 mast (http://www.fino3.de). 
744 Dr. Vicente Buendia-Ramon of University of Valencia (Spain) is also warmly thanked for his 745 support in applying the free, open-source Living for SOM tool (http://livingforsom.com) used for 746 all SOM computations. 


\section{References}

[1] Hu S, Cheng J. Performance evaluation of pairing between sites and wind turbines. Renew Energy 2007;32(11):1934-47.

[2] Chang TP, Cheng SP, Liu FJ, Sun LC, Chang YP. Site matching study of pitch-controlled wind turbine generator. Energy Conv Manage 2014;86:664-9.

[3] Jangamshetti SH, Rau VG. Normalized power curves as a tool for identification of optimum 755

[4] Billinton R, Chen H. Determination of the optimum site-matching wind turbine using risk756 based capacity benefit factors. IEE Proceedings-Generation, Transmission and Distribution 1999;146(1):96-100.

[5] Fuglsang P, Bak C, Schepers JG, Bulder B, Cockerill TT, Claiden P, et al. Site-specific design 759 optimization of wind turbines. Wind Energy 2002;5(4):261-79.

[6] Pallabazzer R. Parametric analysis of wind siting efficiency. J. Wind Eng. Ind. Aerodyn. 2003;91(11):1329-52.

[7] Dangar PB, Kaware SH, Katti PK. Site matching of offshore wind turbines - A case study. In: World Renewable Energy Congress 2011, 8-13 May 2011, Linköping, Sweden.

[8] Diaf S, Notton G. Evaluation of electricity generation and energy cost of wind energy 765 conversion systems in southern Algeria. Renew Sust Energ Rev 2013;23:379-90.

[9] Carrillo C, Montaño AO, Cidrás J, Díaz-Dorado E. Review of power curve modelling for wind turbines. Renew Sust Energ Rev 2013; 21:572-81.

[10] Chang TJ, Wu YT, Hsu HY, Chu CR, Liao CM. Assessment of wind characteristics and wind turbine characteristics in Taiwan. Renew Energy 2003;28:851-71.

[11] El-Shimy M. Optimal site matching of wind turbine generator: Case study of the Gulf of Suez region in Egypt. Renew Energy 2010;35(8):1870-8. 
[12] Abul'Wafa AR. Matching wind turbine generators with wind regime in Egypt. Electric Power Systems Research 2011;81(4):894-8.

[13] Perkin S, Garrett D, Jensson P. Optimal wind turbine selection methodology: A case-study for Búrfell, Iceland. Renew Energy 2015;75:165-72.

[14] Diveux T, Sebastian P, Bernard D, Puiggali J, Grandidier J. Horizontal axis wind turbine systems: optimization using genetic algorithms. Wind Energy 2001;4:151-71.

[15] Lee K-H, Joo W, Kim K-H, Lee D-H, Lee K-T, Park J. Numerical optimization using improvement of the design space feasibility for Korean offshore horizontal axis wind turbine blade. In: European wind energy conference \& exhibition (EWEC) 2007.

[16] Zobaa A, Bansal R. Handbook of renewable energy technology. Singapore: World Scientific; 2011.

[17] Fuglsang P, Madsen HA. Optimization method for wind turbine rotors. J. Wind Eng. Ind. Aerodyn. 1999;80:191-206.

[18] Maki K, Sbragio R, Vlahopoulos N. System design of a wind turbine using a multi-level optimization approach. Renew Energy 2012;43:101-10.

[19] Mirghaed MR, Roshandel R. Site specific optimization of wind turbines energy cost: iterative approach. Energy Conv Manage 2013;73:167-75.

[20] Ashuri T, Zaaijer MB, Martins JR, Zhang J. Multidisciplinary design optimization of large wind turbines-Technical, economic, and design challenges. Energy Conv Manage $2016 ; 123: 56-70$.

[21] Chehouri A, Younes R, Ilinca A, Perron J. Review of performance optimization techniques applied to wind turbines. Appl Energy 2015;142:361-88.

[22] Kohonen T. The self-organizing Map. Neurocomputing 1998:21:1-6.

[23] Beccali M, Cellura M, Brano VL, Marvuglia A. Forecasting daily urban electric load profiles using artificial neural networks. Energy Conv Manage 2004;45(18):2879-900. 
[24] Sideratos G, Hatziargyriou ND. An advanced statistical method for wind power forecasting. IEEE Transactions on Power Systems 2007;22(1):258-65.

[25] Sheela KG, Deepa SN. Neural network based hybrid computing model for wind speed prediction. Neurocomputing 2013;122:425-9.

[26] Beccali M, Cirrincione G, Marvuglia A, Serporta C. Estimation of wind velocity over a complex terrain using the Generalized Mapping Regressor. Appl Energy 2010;87(3):884-93.

[27] Lapira E, Brisset D, Ardakani HD, Siegel D, Lee J. Wind turbine performance assessment using multi-regime modeling approach. Renew Energy 2012;45:86-95.

[28] Wenyi L, Zhenfeng W, Jiguang H, Guangfeng W. Wind turbine fault diagnosis method based on diagonal spectrum and clustering binary tree SVM. Renew Energy 2013;50:1-6.

[29] Cook NJ. The Deaves and Harris ABL model applied to heterogeneous terrain. J. Wind Eng. Ind. Aerodyn. 1997;66(3):197-214.

[30] Gualtieri G. Surface turbulence intensity as a predictor of extrapolated wind resource to the turbine hub height. Renew Energy 2015;78:68-81.

[31] Justus CG, Hargraves WR, Yalcin A. National assessment of potential output from windpowered generators, J. Appl. Meteorol. 1976;15(7):673-8.

[32] Dahmouni AW, Salah MB, Askri F, Kerkeni C, Nasrallah SB. Assessment of wind energy potential and optimal electricity generation in Borj-Cedria, Tunisia. Renew Sust Energ Rev $2011 ; 15(1): 815-20$.

[33] Stevens MJM, Smulders PT. The estimation of parameters of the Weibull wind speed distribution for wind energy utilization purposes. Wind Eng 1979;3(2):132-45.

[34] Manwell JF, McGowan JG, Rogers, AL. Wind energy explained: theory, design and application. $2^{\text {nd }}$ ed. Chippenham, UK: John Wiley \& Sons; 2010.

[35] Nedaei M, Assareh E, Biglari M. An extensive evaluation of wind resource using new methods and strategies for development and utilizing wind power in Mah-shahr station in Iran. Energy Conv Manage 2014;81:475-503. 
[36] Stull R. Practical meteorology: An algebra-based survey of atmospheric science. ISBN 978-088865-176-1. Univ. of British Columbia, Vancouver, BC, Canada, 2015.

[37] El-Shimy M. Wind Energy Conversion Systems: Reliability Prospective. Encyclopedia of Energy Engineering and Technology 2014;2:2184-206.

[38] Betz A. Introduction to the theory of flow machines. (DG Randall, Trans.) Oxford: Pergamon Press; 1966.

[39] El-Shimy M. Probable power production in optimally matched wind turbine generators. Sust. Energy Technologies and Assessments 2013;2:55-66.

[40] Tavner PJ, Xiang J, Spinato F. Reliability analysis for wind turbines. Wind Energy $2007 ; 10(1): 1-8$.

[41] Hill RR, Stinebaugh JA, Briand D, Benjamin AS, Linsday J. Wind turbine reliability: A database and analysis approach. Sandia National Laboratories, Albuquerque, NM, 2008.

[42] Spera DA. Wind turbine technology: Fundamental concepts of wind turbine engineering. $2^{\text {nd }}$ ed. New York: ASME Press; 2009.

[43] IEA-ETSAP, IRENA. Wind power. Technology brief E07. March 2016. Available at: http://www.irena.org [accessed 23/12/16].

[44] Moné C, Smith A, Maples B, Hand M. 2013 Cost of Wind Energy Review. Golden, CO: NREL Report No. TP- 5000-63267, Feb. 2015.

[45] Snel H. Review of aerodynamics for wind turbines. Wind Energy 2003;6(3):203-11.

[46] Fingersh LJ, Hand MM, Laxson AS. Wind turbine design cost and scaling model. Golden, CO: NREL Report No. TP-500-40566, Dec. 2006.

[47] Kohonen T, Oja E, Simula O, Visa A, Kangas J. Engineering applications of the selforganizing map. Proceedings of the IEEE 1996;84(10):1358-84.

[48] Kohonen T. Self-organizing Maps. $2^{\text {nd }}$ ed. Heidelberg, Germany: Springer; 2001.

[49] Kohonen T. Self-organization of topologically correct feature maps. Biological Cybernetics $1982 ; 43: 59-69$. 
[50] Luyssaert S, Janssens IA, Sulkava M, Papale D, Dolman AJ, Reichstein M, et al. Photosynthesis drives anomalies in net carbon-exchange of pine forests at different latitudes. Global Change Biology 2007;13:2110-27.

852

[51] Vesanto J, Alhoniemi E. Clustering of the self-organizing map. IEEE Transactions on Neural Networks 2000;11(3):586-600.

[52] Jager D, Andreas A NREL National Wind Technology Center (NWTC): M2 Tower; Boulder, CO (Data). NREL Report No. DA-5500-56489, Sep. 1996, http://dx.doi.org/10.5439/1052222 [accessed 23/12/16].

[53] WindPower. The wind turbines and wind farms database, http://www.thewindpower.net; 2016 [accessed 23/12/16].

[54] Gualtieri G. Development and application of an integrated wind resource assessment tool for wind farm planning. Int. J. Renew Energy Research 2012;2(4):674-85.

[55] Arabian-Hoseynabadi H, Oraee H, Tavner PJ. Wind turbine productivity considering electrical subassembly reliability. Renew Energy 2010;35(1):190-7.

[56] Reder MD, Gonzalez E, Melero JJ. Wind turbine failures-tackling current problems in failure data analysis. In: Journal of Physics: Conference Series, 753(7), IOP Publishing, 2016.

[57] Boudia SM, Guerri O. Investigation of wind power potential at Oran, northwest of Algeria. Energy Conv Manage 2015;105:81-92.

[58] Polinder H, Van der Pijl FF, De Vilder GJ, Tavner P. Comparison of direct-drive and geared generator concepts for wind turbines. In: IEEE International Conference on Electric Machines and Drives, 543-50, 2005.

[59] Troen I, Petersen EL. European Wind Atlas. ISBN 87-550-1482-8. Risø National Laboratory, Roskilde, 1989.

[60] Kaski S, Lagus K. Comparing self-organizing maps. In: Proceedings of the International Conference on Artificial Neural Networks (ICANN '96), Springer, Berlin, Germany, 1996:809-14. 

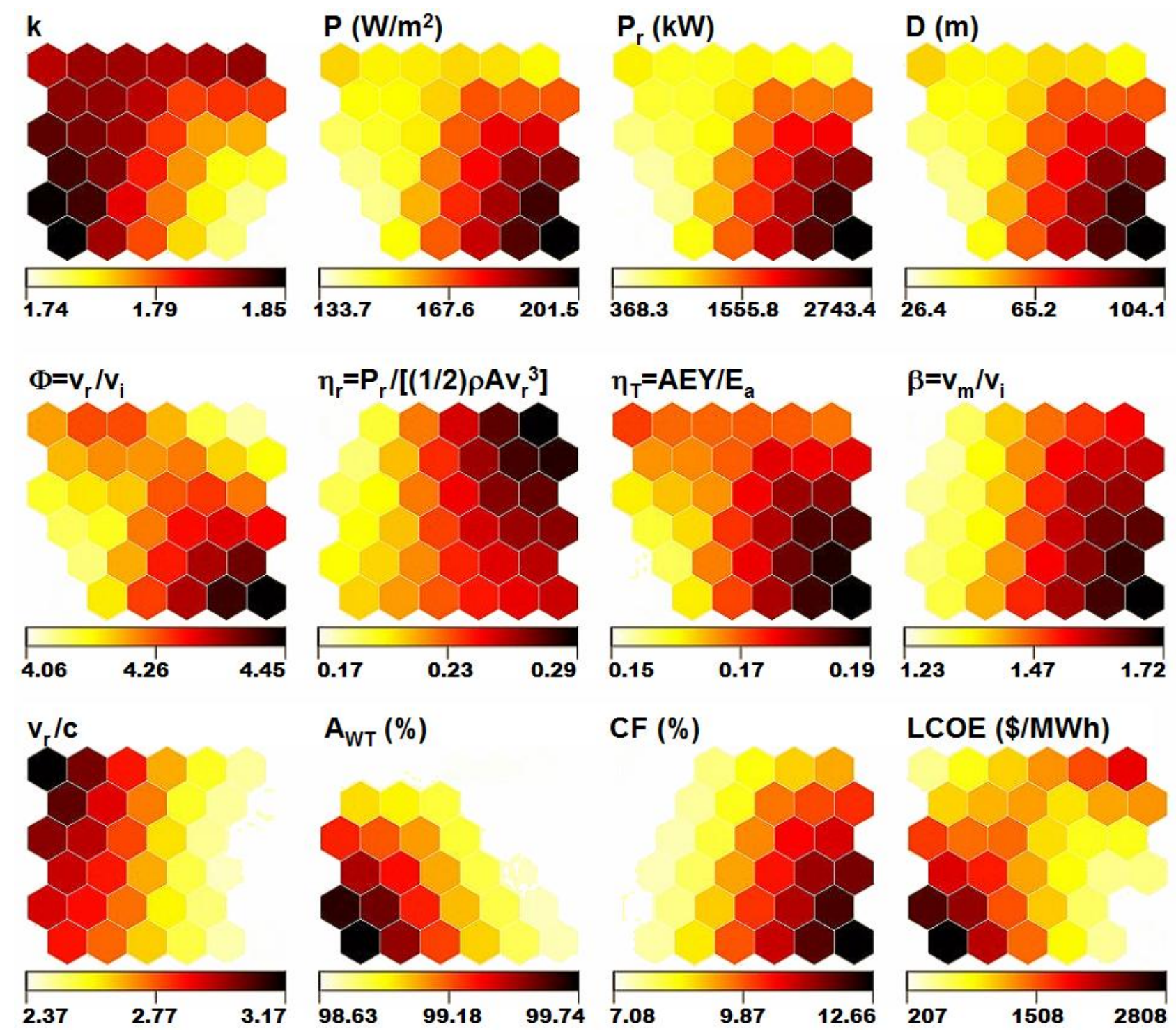

LCOE (\$/MWh)

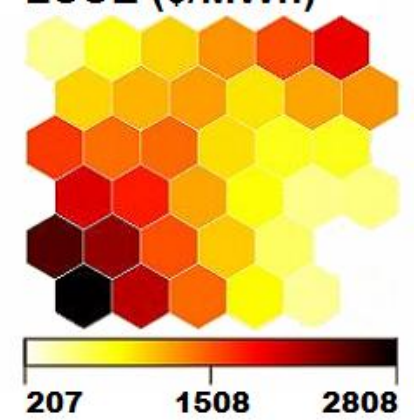

